\title{
Glycopolymers from Saccharomyces Cerevisiae BIM Y-195 with Unusual Immunochemical Properties: Isolation, Structural Identification and Prediction of Their Role in Pathogenesis/Treatment of Autoimmune Thyroid Diseases
}

\author{
E. P. Kiseleva ${ }^{1}$, K. I. Mikhailopulo ${ }^{1}$, G.I. Novik ${ }^{2}$, E. Szwajcer Dey ${ }^{3}$, E. L. Zdorovenko ${ }^{4}$, \\ A. S. Shashkov ${ }^{4}$ and Y. A. Knirel ${ }^{4}$ \\ ${ }^{1}$ The Institute of Bioorganic chemistry, National Academy of Sciences of Belarus, Minsk, Republic of \\ Belarus \\ ${ }^{2}$ The Institute of Microbiology, National Academy of Sciences of Belarus, Minsk, Republic of Belarus \\ ${ }^{3}$ Lund University, Division of Pure and Applied Biochemistry, Sweden
}

${ }^{4}$ N.D. Zelinsky Institute of Organic Chemistry, Russian Academy of Sciences, Moscow, Russia

Correspondence should be addressed to: E. P. Kiseleva; epkiseleva@yandex.ru

Received Date: 22 September 2013; Accepted Date: 11 December 2013; Published Date: 28

February 2014

Academic Editor: Sergey V. Suchkov

Copyright (C) 2014 E. P. Kiseleva, K. I. Mikhailopulo, G. I. Novik, E. Szwajcer Dey, E. L. Zdorovenko, A. S. Shashkov and Y. A. Knirel. Distributed under Creative Commons CC-BY 3.0Contact author:

\begin{abstract}
Molecular mimicry in the broad sense is structural, functional or immunologic similarity between unrelated macromolecules (Oldstone, 1998). In biomedical studies this phenomenon is discussed as the most proven mechanism of triggering/prevention of autoimmune diseases (Kivity et al., 2009). In this paper, we isolate and structurally identify the yeast biopolymers (BPs) that selectively bind human autoantibodies to thyroid peroxidase (TPO) and thyroglobulin (Tg) (anti-TPO and anti-Tg, respectively), e.g. immunologically mimic thyroid antigens. The BPs, viz., $\mathrm{BP}_{\text {anti-TPo }}$ and $\mathrm{BP}_{\text {anti-Tg, }}$, were isolated from the soluble fraction of S. cerevisiae BIM Y-195 by affinity chromatography with anti-TPO or anti-Tg, respectively. Both affinity eluates, $\mathrm{AE}_{\text {anti-TPo }}$ and $\mathrm{AE}_{\text {anti-Tg, }}$, showed functional activity characteristic of $\mathrm{BP}_{\text {anti-TPo }}$ and $\mathrm{BP}_{\text {anti-Tg, }}$ viz, ability (i) to distinquish anti-TPO (anti-Tg) from other IgG and (ii) to compete with TPO (Tg) for binding of anti-TPO (anti-Tg) in ELISA tests. The semi-preparative size exclusion chromatography of $\mathrm{AE}_{\text {anti-TPo }}$ and $\mathrm{AE}_{\text {anti-Tg }}$ with detection by refractometer gave a 5000-7000 Da fractions containing pure $\mathrm{BP}_{\text {anti-TPo }}$ and $\mathrm{BP}_{\text {anti-Tg, }}$, respectively, according to ELISA data. Analysis by two-dimensional NMR spectroscopy including ${ }^{1} \mathrm{H},{ }^{1} \mathrm{H}$ COSY and ${ }^{1} \mathrm{H},{ }^{13} \mathrm{C}$ HSQC experiments indicated that both substances are linear $\alpha$-1, 6-glucans.
\end{abstract}

Cite this Article as: E. P. Kiseleva, K. I. Mikhailopulo, G. I. Novik, E. Szwajcer Dey, E. L. Zdorovenko, A. S. Shashkov and Y. A. Knirel (2014), "Glycopolymers from Saccharomyces Cerevisiae BIM Y-195 with Unusual Immunochemical Properties: Isolation, Structural Identification and Prediction of Their Role in Pathogenesis/Treatment of Autoimmune Thyroid Diseases," Research in Immunology: An International Journal, Vol. 2014 (2014), Article ID 355367, DOI: 10.5171/2014.355367 
It was shown for the first time an immunological similarity (molecular mimicry) of $\alpha-1,6$ glucans of $S$. cerevisiae BIM Y-195 and human thyroid proteins, TPO and Tg, just as it was shown early for $\alpha$-1, 6-glucans of Bifidobacterium bifidum BIM B-733D and TPO/Tg (Kiseleva et. al., 2013). On the whole, our data point to a possible role of wine yeast in the pathogenesis/treatment of autoimmune thyroid diseases (ATD).

Keywords: $\alpha-1,6$-glucan, autoantibodies, molecular mimicry.

\section{Introduction}

In the industrialized world, the most common causes of morbidity and mortality in 20th century became chronic diseases (Alberti, 2001; Heath, 2009). A special group of them are autoimmune diseases, affecting up to $5 \%$ of the population of the Western countries (Kivity et al., 2009). Autoimmune thyroid diseases (ATD) are the most common form of autoimmune diseases (Canaris et al., 2000; Cooper and Stroehla, 2003; Vanderpump et al., 1995). The clinical manifestations of ATD vary from thyroid hyperactivity (Graves' disease) to thyroid underactivity (chronic autoimmune thyroiditis or Hashimoto's thyroiditis, HT); term HT is used ordinary as a synonym of ATD. The two primary antigens in ATD are thyroglobulin (Tg) and thyroid peroxidase (TPO). The glycoprotein $\operatorname{Tg}(660 \mathrm{kDa})$ is the storage form of thyroid hormones within the thyroid follicle. TPO is an enzyme expressed at the apical border of the thyroid cells and catalyzes key reactions of thyroid hormones biosynthesis. The clinical diagnosis of ATD depends on physical and biochemical abnormalities as well as serological detection of autoantibodies to the antigens (anti-TPO and anti-Tg) (Davies and Amino, 1993).

It is generally accepted that ATD result from a complex interaction between genetic and environmental factors, most of which have not been identified. Eighty percent of the susceptibility to develop ATD are genetically determined and the immune-regulatory/thyroid-specific genes implicated in pathogenesis of ATD are identified (Ringold et al., 2002; Simmonds and Gough, 2004; Tomer, 2010). Environmental factors include excess dietary iodine; selenium deficiency; naturally occurring goitrogens found in the legumes and other plants; certain drugs such as amiodarone, lithium and interferon- $\alpha$; synthetic chemicals such as pesticides, by-products of industry (polyaromatic hydrocarbons, polyhalogenated biphenols) and pollutants associated with smoking (Burek and Talor, 2009; Davies, 2008; Duntas, 2008). Interestingly, that the European literature shows the increasing incidence of HT during last decades, which supports the conclusion about role of environmental factors in triggering of the disease (Rizzo et al, 2010).

Different types of an infection have a special place among environmental factors implicated in the pathogenesis of ATD. Published reports involving serological data from human studies and suggesting association of ATD with seroreactivity against influenza virus, hepatitis $\mathrm{C}$ virus, enterobacteria, streptococci, staphylococci, Yersinia enterocolitica, Helicobacter pilori and protozoa Toxoplasma gondii have been reviewed (Tozzoli et al., 2008). Serologically detected infection agents also include Mycoplasma sp. (Sack, 1989) and herpes simplex virus (Thomas et al., 2008a). Direct evidences of retrovirus or herpes simplex virus DNA in the thyroid of ATD patients are rare and controversial (Al-Zarzour and Monem, 2011; Thomas et al., 2008b; Tomer and Villanueva, 2004). The homology between thyroid antigens and some proteins of Yersinia enterocolitica, Borrelia burgdorferi (Benvenga et al., 2006), E. coli (McLachlan and Rapoport, 1989) and hepatitis $C$ virus (Martocchia and Falaschi, 2007) was established by an in silico analysis. Molecular mimicry of thyroid antigens by these microorganisms was proposed as a mechanism of ATD triggering. The fertilefield hypothesis explains how different microbial infections induce and exacerbate a single autoimmune disease (Von Herrath et al., 2003). 
Multiple and mutually non-exclusive mechanisms, by which host infection by a pathogen can lead to autoimmunity were proposed: (i) molecular mimicry, (ii) epitope spreading owing to infective lysis of tissue, (iii) bystander activation, (iv) presentation of proteolytically formed cryptic self-epitopes (Ercolini and Miller, 2009; Getts and Miller, 2010; Münz et al., 2009). An adjuvant effect of pathogens (Getts and Miller, 2010; Rose, 2008) acting through pathogen-associated molecular patterns receptors (Den Dunnen et al., 2010; Jeong and Lee, 2011; Kawai and Akira, 2009; Zeuthen et al., 2008) or nonspecific activation of immune system by bacterial superantigens (Münz et al., 2009) should also be taken into account.

The most plausible explanation of the role of microorganisms in the provocation of autoimmune diseases is molecular mimicry, i.e., the emergence of autoreactive clones of $\mathrm{T}$ - and B-lymphocytes as a result of cross-immune response to homologous bacterial or viral antigen (Harkiolaki et al., 2009; Kohm et al., 2003; Roep, 2003; Wegner et al., 2009).

Under enhanced gut permeability for relatively high-molecular substances and even for whole cells of bacteria (Bruewer et al., 2003), known as "leaky gut" (Clayburgh et al, 2004), the list of microorganisms that could potentially influence the autoimmune process may be expended by intestinal symbionts.

In present study, the yeasts $S$. cerevisiae and $D$. hansenii are interesting for several reasons. Firstly, both yeasts are recognized antibiotic-resistant human commensals though their presence in the human gut has a transient character (Pecquet et al., 1991). People commonly consume live $S$. cerevisiae cells with sweet fruits and dairies including koumiss and acidophilus yeast milk (Wszolek et al., 2006), whereas live $D$. hansenii cells enter the body with cheese (Gori et al., 2012; Sibirny and Voronovsky, 2009) and dry-cured sausages and ham (Andrade et al., 2010; Cano-García et al., 2013). In addition, dried cells of $S$. cerevisiae are frequently used as nutritional supplement, so called "nutritional yeast", that can be found in the most of the natural food stories. Products of processed S. cerevisiae cells (extracts, autolyzates) are widely used as food additives with flavoring properties, whereas yeast cell walls are used either as pharmaceutics to activate the immune system (Jawhara et al., 2012) or as food additives with water-binding properties (Petravić-Tominac et al., 2011). Similarly to widely used $S$. cerevisiae, D. hansenii was found to have enormous biotechnological potential in agro-food sector (Breuer and Harms, 2006; Vetriselvi et al., 2010), which would lead to rapid expansion of their consumption as food additives worldwide.

Secondly, $S$. cerevisiae shares common biotherapeutic properties with allied yeast $S$. boulardii (also known as $S$. cerevisiae var. boulardii (Mitterdorfer et al., 2002; Edwards-Ingram et al., 2007)) (Izadnia et al., 1998; Jahn et al., 1996; van der Aa Kühle et al., 2005), noted probiotic (Kelesidis and Pothoulakis, 2012). For present study, anti-inflammatory and immunomodulatory properties of $S$. cerevisiae are most interesting. The data obtained in animal models show that the administration of $S$. cerevisiae cells induces interleukin 10 (IL-10), which steers the immune system towards a regulatory $\mathrm{T}$ cell response (Generoso et al., 2010; Martins et al., 2009). It may have therapeutic benefits for patients suffering from Th1/Th17mediated autoimmune diseases (in particular, HT) (Phenekos et al., 2004; Qin et al., 2012). In turn, D. hansenii has been found to stimulate immune response in fish (Reyes-Becerril et al., 2012). Moreover, same yeast preparations and substances providing immunomodulation are identified, viz., $\beta$-1-3-glucan (Huang et al., 2009; Pelizon et al., 2005), chitin (Lee et al., 2008), and derivative of yeast cell wall known as zymozan (Kelly et al., 2010); all are shared by $S$. cerevisiae and $D$. hansenii.

Thirdly, specific antibodies to antigens of $S$. cerevisiae are used as serological markers to discriminate between Crohn's disease and ulcerative colitis (Desplat-Jégo et al., 2007). Patients with other intestinal and non-intestinal autoimmune disorders including celiac disease (Ashorn et al., 
2008), autoimmune hepatitis (Czaja et al., 2004), Behçet's disease (Fresko et al., 2005), ATD (Yazıcı et al., 2010; Mankaï et al., 2013) and systemic lupus erythematosus (Dai et al., 2009) also have high seropositivity rates for anti-S. cerevisiae antibodies as compared with healthy donors. Elevated serum levels of anti-S. cerevisiae antibodies do not result primarily from a defect of the gut barrier (Harrer et al., 2004), which allow to assume implication of $S$. cerevisiae in common mechanisms underlying autoimmunity.

In this paper, we isolate and structurally identify the BPs of S. cerevisiae BIM Y-195 that selectively bind human anti-TPO and anti-Tg $\left(\mathrm{BP}_{\text {anti-TPO }}\right.$ and $\mathrm{BP}_{\text {anti-Tg, }}$ respectively). The data on immunologic similarities between thyroid antigens and $\alpha-1,6$-glucans from $S$. cerevisiae point to a role of the wine yeast in the pathogenesis/treatment of ATD.

\section{Materials and Methods}

Methodological Steps of the Study are shown in Appendix 1.

Yeast Cells. S. cerevisiae BIM Y-195 and D. hansenii BIM Y-4 from the Scientific Collection of Model and Industriallyvaluable Non-pathogenic Microorganisms (The Institute of Microbiology NAS of Belarus, Minsk, Republic of Belarus) were used. Both strains were grown on beerwort agar slants at $26^{\circ} \mathrm{C}$ during 3 days. Cells were washed off with $0,15 \mathrm{M} \mathrm{NaCl}$, sedimented by centrifugation at $2000 \times \mathrm{g}$ for $20 \mathrm{~min}$ and weighed. Than cells (20-25 g) were washed $(1 \times 300 \mathrm{~mL})$ with $0.15 \mathrm{M}$ $\mathrm{NaCl}, 0.01 \mathrm{M}$ sodium phosphate, pH 7.5 (buffer 1), separated by centrifugation as stated above and suspended in buffer 1 (50 $\mathrm{mL}$ ). Portions of both cell suspensions (each $0.1 \mathrm{~mL}$ ) were diluted 10 -fold by buffer 1 and immediately used to adjust suspensions to a similar cell concentration.

Adjustment of $S$. Cerevisiae BIM Y-195 and D. Hansenii BIM Y-4 Cell Suspensions to a Similar Cell Concentration. Two series of dilutions were prepared and kept at $37^{\circ} \mathrm{C}$ for $1 \mathrm{~h}$.
One of them contained S. cerevisiae BIM Y195 cell suspension, another one contained D. hansenii BIM Y-4 cell suspension (each 1 - $10 \mu \mathrm{L}$ in $2.5 \mathrm{~mL}$ of $35 \%$ sulfuric acid). Absorption at $260 \mathrm{~nm}$ in a $1 \mathrm{~cm}$ path length $\left(A_{260}\right)$ was measured using $35 \%$ sulfuric acid as a control. The data were expressed as graphs in coordinates " $A_{260}$ " (OY) - "cell suspension in probe, $\mu \mathrm{L}$ " (OX). The slope was calculated for each grapts. The ratio of the slops was used as dilution factor of the suspension that has higher cell concentration. The adjusted suspensions were used to obtain cell fractions.

Cell Fractions. The cells of both strains were used as pre-adjusted suspensions. They were manually homogenized (Wheaton, USA) and ultrasonicated on ice using UZDN-2T (UkrRosPribor, Ukraine) 6 times for $30 \mathrm{~s}$ at a frequency of $22 \mathrm{kHz}$. The cell wall and membrane fractions (CFs) reffered through the text as CF-Sc and CFDh were sedimented by centrifugation at $40000 \times \mathrm{g}$ for $30 \mathrm{~min}$, suspended in buffer $1(50 \mathrm{~mL})$ and immideatly used for ELISA (see ELISA test 1 below). The supernatants (CFFs) reffered through the text as CFF-Sc and CFF-Dh were used for ELISA (see ELISA tests 1 and 2 below). In addition, CFF-Sc was used for biospecific isolation of BPs.

\section{Biospecific Isolation and Purification of the Bacterial Biopolymers. CFF-Sc was divided into two portions and loaded independently on anti-TPO and anti-Tg immobilized on CNBr-activated Sepharose 4B (Pharmacia, Sweden) (Anonymous, 1976). The BPs bound by immobilized autoantibodies were eluted with $0.2 \mathrm{M}$ $\mathrm{NH}_{4} \mathrm{OH}, \mathrm{pH}$ 11.5. The affinity eluates (AEs) referred through the paper as $\mathrm{AE}_{\text {anti-TPO }}$ and $\mathrm{AE}_{\text {anti-Tg }}$ were freeze-dried, tested by ELISA (see ELISA tests 3 and 4 below) and used for BPs purification.}

Dried $\mathrm{AE}_{\text {anti-TPO }}(5 \mathrm{mg}$ ) was dissolved in water $(1 \mathrm{~mL})$ and fractionated on the column $(60 \times 1.6 \mathrm{~cm})$ of TSK-40 gel (Merck, Germany) equilibrated in water. Elution was monitored using a refractometer (Knauer, Germany). Dried $\mathrm{AE}_{\text {anti-Tg }}(5 \mathrm{mg}$ ) was fractionated in a similar way. The fractions corresponding to major peaks in 
each size exclusion chromatography were referred to below as $\mathrm{BP}_{\text {anti-TPO}}-2, \mathrm{BP}_{\text {anti-TPO}}-3$, $\mathrm{BP}_{\text {anti-Tg }}-2$ and $\mathrm{BP}_{\text {anti-Tg- }}-3$ and analyzed by NMR spectroscopy. Fractions $\mathrm{BP}_{\text {anti-TPO- }} 2$ and $\mathrm{BP}_{\text {anti-Tg- }} 2$ were tested by ELISA (see ELISA tests 5 and 6 below).

Human Serum Samples were obtained from the Minsk City Clinical Oncologic Dispensary (Republic of Belarus) and tested using the ELISA kits for anti-TPO and anti-Tg (Xema Co. Ltd, Russia). Serum samples were divided into three groups according the data of ELISA. The first group was from healthy donors without clinical manifestations of ATD. Concentrations of anti-TPO and anti-Tg in these samples were less than the upper limits for healthy donors, viz., $50 \mathrm{IU} / \mathrm{ml}$ and $100 \mathrm{IU} / \mathrm{ml}$, respectively. The second and third groups included samples of blood serum of patients with clinically confirmed diagnosis of ATD. Concentrations of anti-TPO and anti-Tg in the samples of the second group were in the range $100-500 \mathrm{IU} / \mathrm{ml}$ and 200 - $500 \mathrm{IU} / \mathrm{ml}$, respectively. The concentrations of antibodies to each thyroid antigen in the samples of the third group were higher than $500 \mathrm{IU} / \mathrm{ml}$. Selected serum samples were used to prepare probes "healthy" and "ATD" and for ELISA test 1.

Serum Probes "Healthy" and "ATD” were prepared by combining 10 samples from the first group ("healthy") and combining 10 samples from the third group ("ATD"). Quantification of anti-TPO and anti-Tg in both probes was performed using the appropriate test kits for ELISA (Xema Co. Ltd, Russia). Probe "healthy" contained 25 $\mathrm{IU} / \mathrm{mL}$ anti-TPO plus $52 \mathrm{IU} / \mathrm{mL}$ anti-Tg, probe "ATD" contained $1200 \mathrm{IU} / \mathrm{mL}$ antiTPO plus 1500 IU/mL anti-Tg. Probe "healthy" was used for ELISA tests 2 and 3 and isolation of total human IgG. Probe "ATD" was used for ELISA tests 2 - 4 and isolation of anti-TPO and anti-Tg.

Total Human Immunoglobulins of Class G (IgG) were isolated from serum probe "healthy". The Igs were precipitated with ammonium sulfate $(40 \%$ saturation of serum); the precipitate was dissolved in buffer 1 and ammonium sulfate was removed by dialysis against the same buffer. The IgG were separated from crude Ig extract by affinity chromatography on Protein G Agarose (Pierce, USA) in accordance with product instruction manual. The anti-TPO and anti-Tg were removed by affinity chromatography using TPO or Tg, respectively (Tsyganova et al., 2006a) immobilized on CNBr-activated Sepharose 4B. IgG concentration was determined spectrophotometrically, where $D_{280 \mathrm{~nm}, 1 \mathrm{~cm}, 1 \mathrm{mg} / \mathrm{ml}}=1.35$. Total $\mathrm{IgG}$ (without anti-TPO and anti-Tg) were used as a control probe in ELISA (see ELISA tests 5 and 6).

\section{Autoantibodies to Thyroid Antigens} were isolated from serum probe "ATD" by affinity chromatography with either TPO or Tg (Tsyganova et al., 2006a) immobilized on CNBr-activated Sepharose 4B (Pharmacia, Sweden) (Anonymous, 1976). Quantification of pure anti-TPO and anti-Tg was performed using the appropriate ELISA kits (Xema Co. Ltd, Russia). Additionally, concentrations of pure antiTPO and anti-Tg were determined spectrophotometrically as stated above for pure total Igs. Pure anti-TPO and anti-Tg were used for (i) affinity gel synthesis and (ii) ELISA (see ELISA tests 5 and 6 below). Serum samples for antibodies isolation and purified anti-TPO (anti-Tg) were stored at $-20^{\circ} \mathrm{C}$ and defrosted once immediately before use.

Thyroid Antigens. TPO and Tg were isolated from human thyroid tissue of patients with Graves' disease obtained from the Minsk City Clinical Oncologic Dispensary (Republic of Belarus). The soluble fraction of thyroid homogenate after sedimentation of nuclei, mitochondria and microsomes was used as source of TPO (Tsyganova et al., 2006b) and Tg. TPO was purified by affinity chromatography with mouse monoclonal antibodies (MAb) A1 and F8 (Tsyganova et al., 2006c) immobilized on CNBr-activated Sepharose 4B. Tg was isolated by ammonium sulfate (60\% saturation) precipitation and gelfiltration of dissolved precipitate on P-200 (Bio-Rad, USA) (Simionescu et al., 1983). Purity of TPO and Tg was not less than 95\% according to SDS-PAGE. TPO and Tg 
were used for affinity gel synthesis and ELISA tests 1, 3-6.

ELISA. General ELISA protocol. Each item (TPO, Tg, CF-Sc, CF-Dh, CFF-Sc, CFF-Dh, $\mathrm{AE}_{\text {anti-TPO}}, \mathrm{AE}_{\text {anti-Tg, }} \mathrm{BP}_{\text {anti-TPO}}-2, \mathrm{BP}_{\text {anti-Tg}}-2$, human serum albumin (HSA) (Sigma, USA) and protein A from Staphyllococcus aureus (Sigma, USA) was immobilized by passive adsorption on polystyrene microplates (Greiner bio-one, Germany) at $4^{\circ} \mathrm{C}$ overnight $(0.1 \mathrm{~mL}$ per well). TPO and Tg were immobilized from solutions of $0.1 \mathrm{M}$ $\mathrm{NaHCO}_{3}, \mathrm{pH}$ 8.3, and $0.1 \mathrm{M}$ citratephosphate buffer, pH 5.5, respectively, containing $0.5 \mathrm{mg} / \mathrm{L}$ of the appropriate antigen. Protein A and HSA were immobilized from $0.01 \mathrm{M}$ sodium phosphate buffer, pH 7.5 that contained 1 $\mathrm{mg} / \mathrm{L}$ of the protein. Cell fractions of both strains (each pre-diluted 50-fold) were immobilized from $0.01 \mathrm{M}$ sodium phosphate buffer, pH 7.5, with $A_{260}$ values of 0.05 in a $1 \mathrm{~cm}$ pathlength. Both AEs (each $1 \mathrm{mg} / \mathrm{L}$ ), $\mathrm{BP}_{\text {anti-TPO}}-2$ and $\mathrm{BP}_{\text {anti-Tg-2 }}$ (each $(0.4-2) \mathrm{mg} / \mathrm{L}$ ) were immobilized from solutions of $0.05 \mathrm{M}$ ammonium acetate, pH 8.5, supplemented with $1 \mathrm{mM}$ $\mathrm{CaCl}_{2}$ (buffer 2). The wells were washed (3 $\times 300 \mu \mathrm{L}$ per well) with buffer 1 after immobilization and each stage of the analysis.

The immunochemical reactions were initiated by addition of solutions $0.1 \mathrm{~mL}$ per well) of primary reagents (selected serum samples, probe "healthy", probe "ATD" and "ATD" plus thyroid antigen, pure anti-TPO and anti-Tg, pute total IgG) in buffer 1 supplemented with $0.2 \%$ phenol and 3\% casein (buffer 3) (first ELISA stage). Immobilized items and primary reagents added in wells at the first stage of ELISA tests are shown in Appendix 2.

The enzymatic conjugates $0.1 \mathrm{~mL}$ per well) in buffer 1 supplemented with $1 \%$ bovine serum albumin (Sigma, USA) were used as a developing reagents (second ELISA stage). All incubations were performed during $1-2 \mathrm{~h}$ at $37^{\circ} \mathrm{C}$. The enzymatic peroxidation reaction was initiated by addition of $0.1 \mathrm{~mL}$ per well 3 , 3',5,5'-tetramethylbenzidine liquid substrate system (Sigma, USA). The reaction was stopped by addition of $0.1 \mathrm{~mL}$ per well $4.8 \% \mathrm{H}_{2} \mathrm{SO}_{4}$. The $A_{450}$ values were measured in each well using the automatic multi-channel spectrophotometer (Uniplan, Russia).

ELISA test 1 was performed to detect functional activity characteristic of $\mathrm{BP}_{\text {anti- }}$ TPO and $\mathrm{BP}_{\text {anti-Tg in cell fractions of both }}$ strains and thereupon select strain and cell fraction for BPs isolation. We used immobilized (i) CF-Sc, (ii) CF-Dh, (iii) CFFSc, (iv) CFF-Dh, (v) TPO and (vi) Tg ( 96 wells for each item). Human serum samples from the second and the third groups $(n=48)$ were used as a source of anti-TPO and anti-Tg. They were diluted 100 -fold by buffer 3 and added into appropriate wells (in duplicates) containing each of the immobilized items $i$ - vi. The bound Igs were detected by means of MAb against human IgG conjugated with horseradish peroxidase (MAb-anti IgG HRP) (Xema Co. Ltd, Russia) and the data set of $A_{450}$ values ( $\mathrm{n}=48$, each in duplicates) was obtained for each immobilized item. The correlations between the two data sets (one data set related to every one of cell fractions $(i-i v)$ and another one related to TPO) were calculated by means of Excel. Similar correlations were calculated using the data set related to $\mathrm{Tg}$ instead of the data set related to TPO.

ELISA test 2 was performed to validate selection of CFF-Sc for BPs isolation. Immobilized (i) CFF-Sc, (ii) protein A and (iii) HSA (20 wells for each item) were used. Two series of dilutions were prepared. One of them contained probe "ATD", another one contained probe "healthy" (each (0.06-1) \%). The dilutions were added into appropriate wells (in duplicates) containing each of the immobilized items $i$ - iii. The bound Igs were detected by means of MAb-anti IgG HRP (Xema Co. Ltd, Russia) (wells $i$ and ii) and conjugate of protein $\mathrm{L}$ from Peptostreptococcus magnus with HRP (protein L - HRP) (Sigma, USA) (wells iii). 
ELISA test 3 was performed to confirm that $\mathrm{AE}_{\text {anti-TPO }}$ and $\mathrm{AE}_{\text {anti-Tg }}$ contain substances, interacting selectively with anti-TPO and anti-Tg, respectively. Immobilized (i) $\mathrm{AE}_{\text {anti- }}$

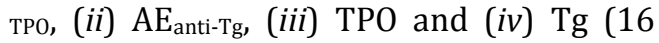
wells for each item) were used. Two series of dilutions were prepared. One of them contained probe "ATD", another one contained probe "healthy" (each (0.04 - 1) $\%)$. The dilutions were added into appropriate wells (in duplicates) containing each of the immobilized items $i$ - iv. The bound Igs were detected by means of MAb-anti IgG - HRP (Xema Co. Ltd, Russia).

ELISA test 4 (competitive) was performed to confirm that $\mathrm{AE}_{\text {anti-TPO }}$ and $\mathrm{AE}_{\text {anti-Tg }}$ contain substances, competing with TPO and $\mathrm{Tg}$, respectively, for binding of the appropriate antibodies. We used the same immobilized items $i$ - $i v$ as in test 3 (8 wells for each item). Probe "ATD" was diluted 1000 -fold and $0.05 \mathrm{~mL}$ was added into all wells. Next, $0.05 \mathrm{~mL}$ of buffer 3 was added into two wells containing each of the immobilized items $i-i v$ (to give $\mathrm{B}_{0}$ experimental points). Three TPO dilutions (40, 120 and $360 \mathrm{mg} / \mathrm{L}$; each $0.05 \mathrm{~mL}$ ) were added into strips $i$ and iii (in duplicates) to give $B_{1}, B_{2}$ and $B_{3}$ experimental points, respectively. Three Tg solutions $(33,100$ and $300 \mathrm{mg} / \mathrm{L}$; each 0.05 $\mathrm{mL}$ ) were added into strips $i i$ and iv (in duplicates) to give $B_{1}, B_{2}$ and $B_{3}$ experimental points, respectively. The bound Igs were detected by means of MAbanti IgG - HRP (Xema Co. Ltd, Russia). The data for each immobilized item were calculated as $\left(\mathrm{B}_{\mathrm{n}} / \mathrm{B}_{0}\right) \times 100, \%$.

ELISA test 5 was performed to confirm functional activity of $\mathrm{BP}_{\text {anti-TPO}}-2$. We used immobilized (i) $\mathrm{BP}_{\text {anti-TPO-2, (ii) TPO and }}$ (iii) protein A from Staphyllococcus aureus (Sigma, USA) (16 wells for each item). Two series of dilutions were prepared. One of them contained pure anti-TPO, second one contained pure total IgG without anti-TPO and anti-Tg (each $(1.3-35) \mathrm{mg} / \mathrm{L})$. The dilutions were added into appropriate wells (in duplicates) containing immobilized items $i$ - iii. The bound Igs were detected by means of MAb-anti IgG HRP (Xema Co. Ltd, Russia) (wells $i$ and ii) and protein L - HRP (Sigma, USA) (wells iii).

ELISA test 6 was performed to confirm functional activity of $\mathrm{BP}_{\text {anti-Tg- }}-2$. We used

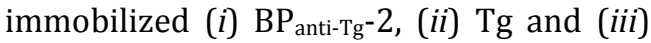
protein A from Staphyllococcus aureus (Sigma, USA) (16 wells for each item). Test was performed similarly to test 5 ; pure anti-Tg $(1.2-32) \mathrm{mg} / \mathrm{L})$ were used instead of pure anti-TPO.

NMR Spectroscopy. NMR spectra were recorded on a Bruker Avance II 600 spectrometer at $30^{\circ} \mathrm{C}$ using a $5 \mathrm{~mm}$ broadband inverse probe head for solutions in $99.95 \% \mathrm{D}_{2} \mathrm{O}$ after Deuterium exchange by freeze-drying sample solutions in $99.9 \% \quad \mathrm{D}_{2} \mathrm{O}$. Sodium 3 -(trimethylsilyl)propanoate-2,2,3,3- $\mathrm{d}_{4}\left(\delta_{\mathrm{H}}\right.$ $0.0)$ and acetone $\left(\delta_{C} 31.45\right)$ were used as internal calibration standards for ${ }^{1} \mathrm{H}$ and ${ }^{13} \mathrm{C}$ NMR chemical shifts, respectively. Twodimensional NMR spectra were obtained using standard Bruker software, and Topspin 2.1 program was used to acquire and process the NMR data.

Statistics. Each ELISA test was done as three independent experiments; each well in duplicates. Results were evaluated by standard Student's t test.

\section{Results}

ELISA Testing of S. Cerevisiae BIM Y-195 and D. Hansenii BIM Y-4 Cell Fractions to Detect Functional Activity Characteristic of BP anti-TPo and BP $P_{\text {anti-Tg }}$

S. cerevisiae BIM Y-195 and D. hansenii BIM Y-4 cell suspensions were adjusted to similar cell concentrations before ultrasound treatment for adequate comparison of two strains in subsequent ELISA tests.

Since we shown that yeast cells kept in $35 \%$ sulfuric acid for $1 \mathrm{~h}$ give clear solution with UV adsorption maximum at $260 \mathrm{~nm}$ (Figure 1, A), total nucleic acid concentration quantified by UV absorbance (Gallagher, 2011) was assumed as a measure of cells concentration. We used ratio of the slops shown in Figure $1, \mathrm{~B}$ to 
calculate the dilution factor of the suspension with higher cell concentration for adjustment of two suspensions.

Pre-adjusted cells of $S$. cerevisiae BIM Y195 and D. hansenii BIM Y-4 were disrupted by ultrasound treatment and fractionated by high speed centrifugation. Cell fractions of two yeast strains (CF-Sc, CFF-Sc, CF-Dh and CFF-Dh) were immobilized on microplates and tested by ELISA to detect functional activity characteristic of $\mathrm{BP}_{\text {anti-TPO, namely the }}$ ability to interact selectively with anti-TPO (ELISA, test 1). In this test we used immobilized TPO as a positive control and human serum samples $(n=48)$ from the second and third groups as source of antiTPO. The bound Igs were detected by means of MAb-anti IgG - HRP since antiTPO are generally of IgG class (Xie et al.,

A

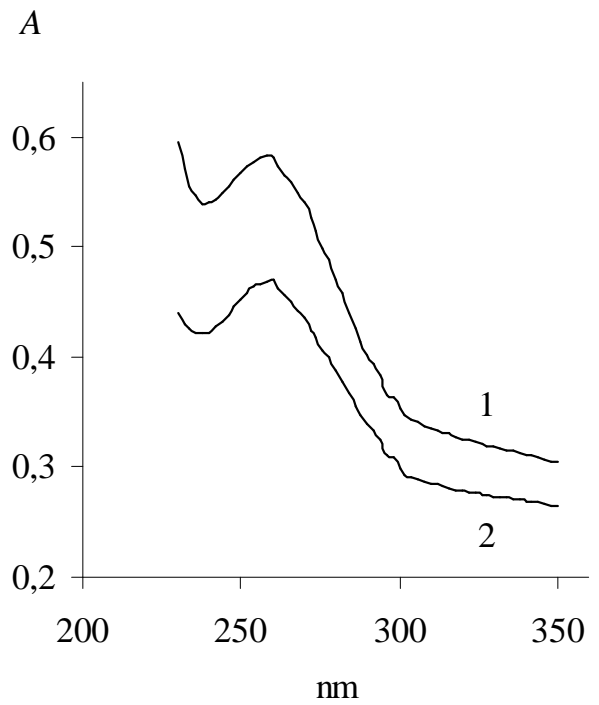

2008). The data sets of values $A_{450}(\mathrm{n}=48)$ obtained for each immobilized item were used to calculate the correlation coefficients (ELISA, test 1). The calculated data are shown in Table 1.

The same cell fractions were tested by ELISA in a similar way to detect functional activity characteristic of $\mathrm{BP}_{\text {anti-Tg, namely }}$ the ability to interact selectively with antiTg (ELISA, test 1). We used immobilized Tg as a positive control and the same set of human serum samples $(n=48)$ as source of anti-Tg. The bound Igs were detected by means of MAb-anti IgG - HRP since anti-Tg are generally of IgG class (Caturegli et al., 1994; Zhang et al., 2010). Similarly to the previous case, the correlation coefficients were calculated (ELISA, test 1) and shown in Table 1.

B

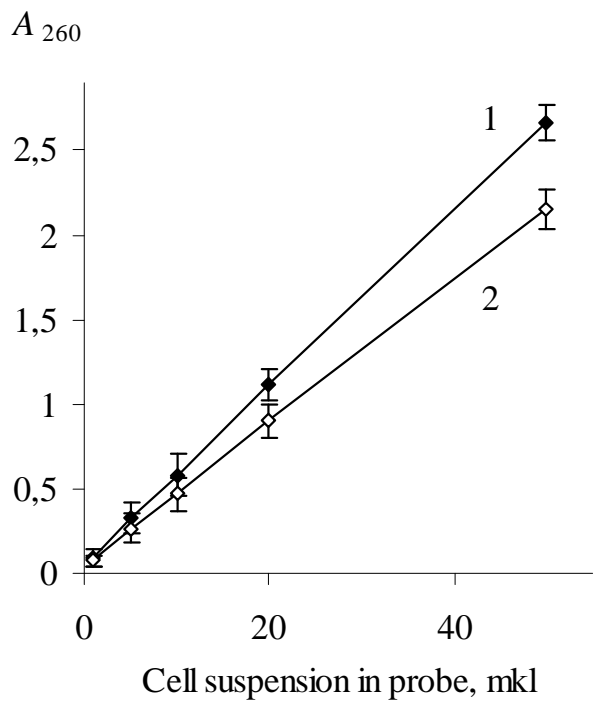

Figure 1. UV Adsorption Spectrum (A) and Adsorption at $260 \mathrm{~nm}$ (B) of S. Cerevisiae BIM Y-195 (1) and D. Hansenii BIM Y-4 (2) Cells Dissolved in 35\% Sulfuric Acid. Representative Data from Three Independent Experiments are Shown. Values are Means \pm Range for Duplicate Tubes. 
Table 1. ELISA Data for Functional Activity Characteristic of $\mathrm{BP}_{\text {anti-TPo }}$ and $\mathrm{BP}_{\text {anti-Tg }}$ in yeast Cell Fractions (ELISA, test 1). The Data are Expressed as Correlation Coefficients. Representative Data from Three Independent Experiments are Shown. Abbreviations: $\mathrm{BP}_{\text {anti-TPo }}$ and $\mathrm{BP}_{\text {anti-Tg }}$ - The Yeast Biopolymers that Selectively Bind Human Autoantibodies to Thyroid Peroxidase and Thyroglobulin.

\begin{tabular}{|l|c|c|c|c|}
\hline Yeast & \multicolumn{2}{|c|}{ S. cerevisiae BIM Y-195 } & \multicolumn{2}{c|}{ D.hansenii BIM Y-4 } \\
\hline Cell fraction & CF & CFF & CF & CFF \\
\hline Correlation with TP0 & 0.56 & $\mathbf{0 . 6 0}$ & 0.25 & 0.28 \\
\hline Correlation with Tg & 0.61 & $\mathbf{0 . 7 3}$ & 0.34 & 0.18 \\
\hline
\end{tabular}

To interpret ELISA data (Table 1), we taken into account that the values of $A_{450}$ in the wells with immobilized TPO and Tg are proportional to the concentration of antiTPO and the anti-Tg, respectively, in serum samples used in ELISA. Consequently, the high correlation coefficients $(\mathrm{r} \geq 0.55)$ related to $\mathrm{CF}-\mathrm{Sc}$ and $\mathrm{CFF}-\mathrm{Sc}$ show that these fractions bind anti-TPO in a concentration-dependent fashion, like immobilized TPO, and thus contain $\mathrm{BP}_{\text {anti- }}$ тPо. Similarly, CF-Sc and CFF-Sc contain $\mathrm{BP}_{\text {anti-Tg. }}$ On the contrary, CF-Dh and CFFDh have considerably lower correlation coefficients and contain neither $\mathrm{BP}_{\text {anti-TPO }}$ nor $\mathrm{BP}_{\text {anti-Tg. }}$

We select CFF-Sc as most preferably fraction for $\mathrm{BP}_{\text {anti-TPO }}$ and $\mathrm{BP}_{\text {anti-Tg }}$ isolation.

\section{ELISA Testing of CFF-Sc to Validate Selection of the Fraction for BPs Isolation}

To prove more convincingly that $\mathrm{CFF}-\mathrm{Sc}$ contains $\mathrm{BP}_{\text {anti-TPO }}$ and $\mathrm{BP}_{\text {anti-Tg, CFF-Sc, }}$ protein A from Staphyllococcus aureus and HSA were immobilized on microplates for ELISA and incubated with solutions of probes "ATD" or "healthy" (ELISA, test 2). We used protein $A$ as a first negative control since it binds total Igs independently on their specificity (Yang et al., 2003) and HSA as a second negative control since it is irrelevant to human Ig on the whole and anti-TPO/anti-Tg specifically.

Total IgG in human serum samples (in our case, in probes "healthy" and "ATD") was assumed to be $7-16 \mathrm{~g} / \mathrm{L}$ (Shakib and Stanworth, 1980). Concentrations of antiTPO and anti-Tg in human serum of ATD patients are in range from 0.05 to $1.4 \mathrm{~g} / \mathrm{L}$ (Beever et al., 1989) and do not exceed $10 \%$ of the concentration of total IgG. Probe "ATD" containing $1200 \mathrm{IU} / \mathrm{mL}$ antiTPO plus $1500 \mathrm{IU} / \mathrm{mL}$ anti-Tg was used as single source of both autoantibodies, since just a few of HT patients have serum antiTPO without anti-Tg (Lindberg et al., 2001). Probe "healthy" containing 25 $\mathrm{IU} / \mathrm{mL}$ anti-TPO plus $52 \mathrm{IU} / \mathrm{mL}$ anti-Tg was used as a negative control, though it has slightly low concentrations of anti-TPO and anti-Tg, so called "natural autoantibodies", which commonly present in serum of healthy donors (Lleo et al., 2010). Both probes were used as (0.06-1) \% dilutions since this concentration range was found to be optimal to analyze substances interacting selectively with anti-TPO and anti-Tg (in our case, $\mathrm{BP}_{\text {anti-TPo }}$ and $\mathrm{BP}_{\text {anti-Tg }}$ ) and to exclude bystander effect of total Igs (Kiseleva et al., 2013). The data are shown in Figure 2.

The data of Figure 2 suggest that CFF-Sc differentiate between probes "healthy" and "ATD" unlike protein A which does not distinguish between the same probes. HSA does not show interaction with both probes at all. We receive evidence that the data of Table 1 do not result from correlation between concentrations of antiTPO (anti-Tg) and anti-S. cerevisiae antibodies (Desplat-Jégo et al., 2007) that were detected with higher frequency in serum samples of ATD pacients as compared to healthy donors (Yazıcı et al., 2010; Mankaï et al., 2013).

Thereupon, we validate selection of CFF-Sc for BPs isolation. 


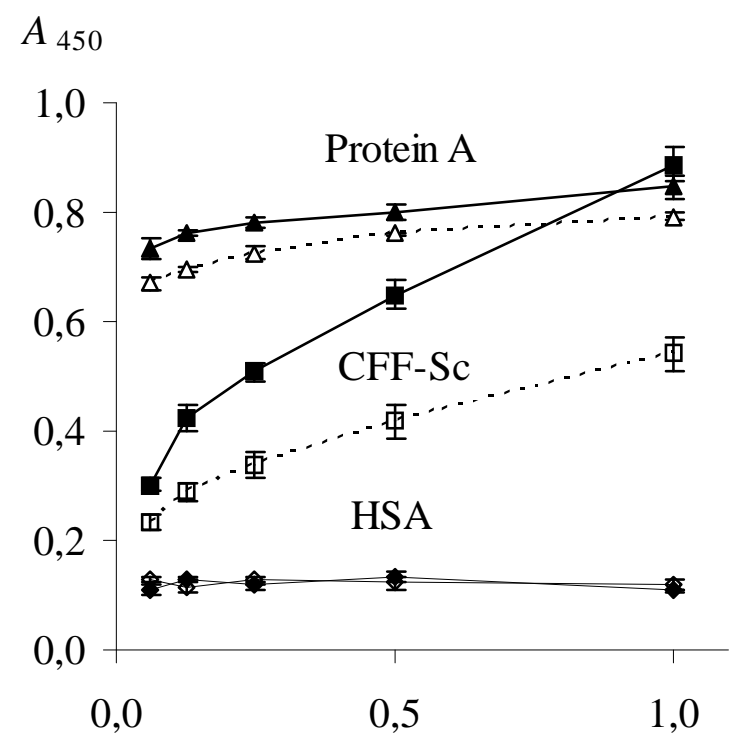

Serum in probe, $\%$

Figure 2. Binding of Human IgG with Immobilized CFF-Sc, Protein A and HSA (ELISA, Test 2). IgG Contained in Serum Probes “ATD” (Black Symbols, Solid Lines) and "Healthy" (Empty Symbols, Dashed Lines) were Used. CFF-Sc Bind Significantly More (p<0.05) IgG from Probe "ATD" as Compared with Control Probe "Healthy". Representative Data from Three Independent Experiments are Shown. Values are Means \pm Range for Duplicate Wells. Abbreviations: CFF-Sc - Cell Free Fraction of S. Cerevisiae BIM Y-195, HSA - Human Serum Albumin, ATD - Autoimmune Thyroid Disease.

ELISA Testing of $A E_{\text {anti-TPo }}$ and $A E_{\text {anti-Tg }}$ to Confirm Isolation of BP ${ }_{\text {anti-TPo }}$ and BPanti-Tg

$\mathrm{BP}_{\text {anti-TPO }}$ and $\mathrm{BP}_{\text {anti-Tg }}$ were isolated from CFF-Sc by affinity chromatogtaphy and referred to below as affinity eluates (AEs), $\mathrm{AE}_{\text {anti-TPO }}$ and $\mathrm{AE}_{\text {anti-Tg, }}$ respectively. $1 \mathrm{mg}$ of each $\mathrm{AE}$ was dissolved in water to prove that we actually isolate $\mathrm{BP}_{\text {anti-TPO }}$ and $\mathrm{BP}_{\text {anti- }}$ $\mathrm{Tg}$, viz., substances that (i) distinquish antiTPO (anti-Tg) from other IgG and (ii) compete with TPO (Tg) for binding of antiTPO (anti-Tg) in ELISA tests.
Direct ELISA test (ELISA, test 3) was performed to confirm that $\mathrm{AE}_{\text {anti-TPo }}$ and $\mathrm{AE}_{\text {anti-Tg }}$ contain substances that distinquish anti-TPO and anti-Tg, respectively, from other IgG. In this test we used immobilized $\mathrm{AE}_{\text {anti-TPO, }} \mathrm{AE_{ \text {anti-Tg, } }}$ TPO and Tg; thyroid antigens were used as a positive controls for $\mathrm{AE}_{\text {anti-TPo }}$ and $\mathrm{AE}_{\text {anti-Tg, }}$ respectively. All immobilized items were incubated with dilutions of probes "ATD" or "healthy". The data are shown in Figure 3. 

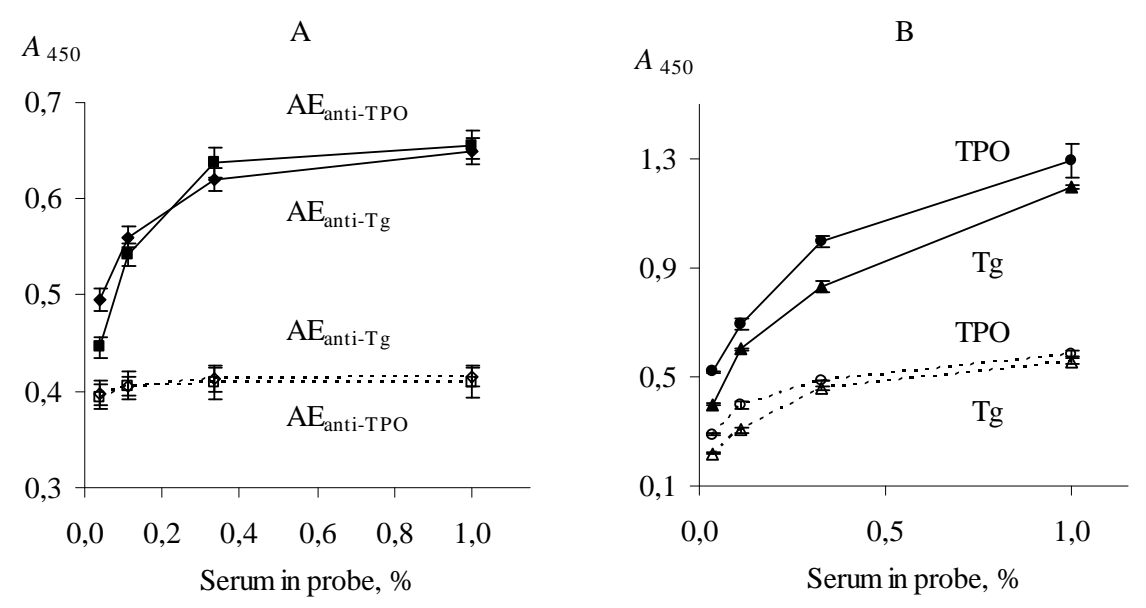

Figure 3. Binding of Human IgG with Immobilized $\mathrm{AE}_{\text {anti-TPo }}$ and $\mathrm{AE}_{\text {anti-Tg }}$ (A), TPO and Tg (B) (ELISA, Test 3). IgG Contained in Serum Probes “ATD” (Black Symbols, Solid Lines) and "Healthy" (Empty Symbols, Dashed Lines) were Used. All Immobilized Items Differenciate between Two Serum Probes $(\mathrm{p}<0.05)$. Representative Data from Three Independent Experiments are Shown. Values are Means \pm Range for Duplicate Wells. Abbreviations: ATD - Autoimmune Thyroid Disease; TPO - Thyroid Peroxidase; Tg -

Thyroglobulin; $\mathbf{A E}_{\text {anti-TPo }}$ and $\mathrm{AE}_{\text {anti-Tg }}$ - Affinity Eluates Obtained from the Soluble Fraction of $S$. Cerevisiae BIM Y-195 Cells by Affinity Chromatography with Either Human Autoantibodies to TPO or Autoantibodies to Tg, Respectively.

The data of Figure 3, A suggest that $\mathrm{AE}_{\text {anti- }}$ TPO and $\mathrm{AE}_{\text {anti-Tg }}$ bind IgG in a concentrationdependent and saturable fashion, like the human thyroid antigens do (Figure 3, B). $\mathrm{AE}_{\text {anti-TPO }}$ and $\mathrm{AE}_{\text {anti-Tg }}$ bind considerably less IgG from probe "healthy" in comparison with IgG from probe "ATD" containing more anti-TPO and anti-Tg (Figure 3, A), in a similar way to immobilized thyroid antigens (Figure 3, B). In whole, the data of Figure 3 prove that $\mathrm{AE}_{\text {anti-TPO }}$ actually binds

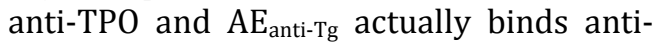
$\mathrm{Tg}$, despite the presence of 10 -fold excess of other IgG.

Competitive ELISA test (ELISA, test 4) was performed to confirm that $\mathrm{AE}_{\text {anti-TPo }}$ and $\mathrm{AE}_{\text {anti-Tg }}$ contain substances competing with TPO and Tg, respectively, for binding to the appropriate antibodies.
The $\mathrm{AE}_{\text {anti-TPO }}$ and TPO as a positive control were immobilized on microplates for ELISA and incubated with probe "ATD" either in the presence of TPO solution or without TPO in liquid phase. Similarly, immobilized $\mathrm{AE}_{\mathrm{anti}-\mathrm{Tg}}$ and $\mathrm{Tg}$ as a positive control were incubated with probe "ATD" either in the presence of $\mathrm{Tg}$ solution or without $\mathrm{Tg}$ in liquid phase. In this test, probe "ATD" was used as a source of anti-TPO and anti-Tg; TPO and Tg in liquid phase were used as a competitors, e.g. substances competing with immobilized items for anti-TPO and anti-Tg binding, respectively. For each immobilized item the data were calculated as $\left(B_{n} / B_{0}\right) \times \cdot 100 \%$, where $B_{n}$ and $B_{0}$ are IgG bound with the immobilized item in the presence and absence of thyroid antigen in liquid phase, respectively. The data are shown in Figure 4. 
A

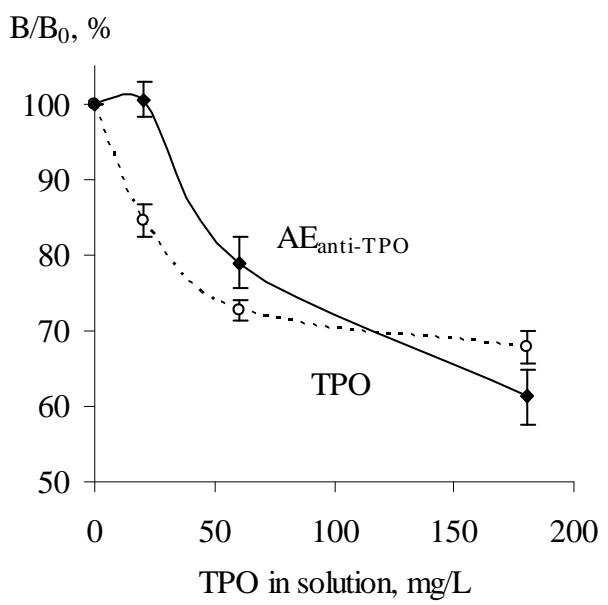

B

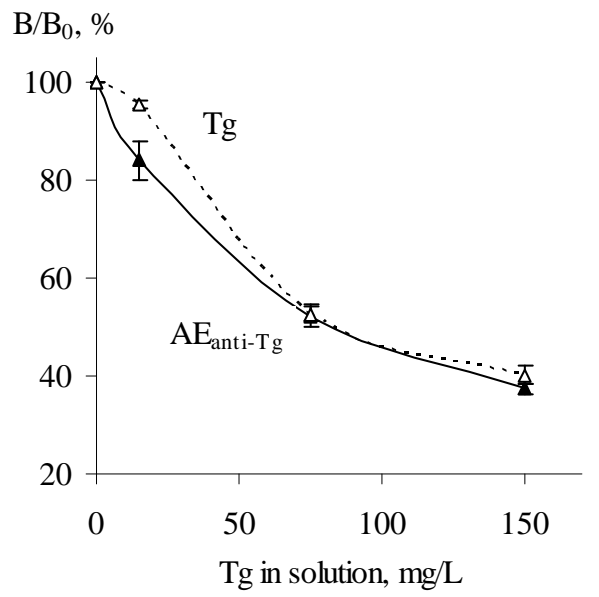

Figure 4. The Competition of Immobilized $\mathrm{AE}_{\text {anti-TPo }}(\mathrm{A})$ and $\mathrm{AE}$ anti-Tg (B) with TPO (A) and Tg (B) Solutions, Respectively, for Binding of IgG Contained in Human Serum Probe “ATD”. Immobilized TPO (A) and Tg (B) were Used as Positive Controls (ELISA, Test 4). $\mathrm{AE}_{\text {anti TPo }}$ and $\mathrm{AE}_{\text {anti-Tg }}$ - Black Symbols, Solid Lines; TPO and Tg - Empty Symbols, Dashed Lines. Mean Data from Three Repeated Experiments are Shown. The Error Bars Represent the Range of Data. Abbreviations: ATD - Autoimmune Thyroid Disease; TPO Thyroid Peroxidase; Tg - Thyroglobulin; $\mathbf{A E}_{\text {anti-TPo }}$ and $\mathbf{A E}_{\text {anti-Tg }}$ - Affinity Eluates Obtained from the Soluble Fraction of $S$. cerevisiae BIM Y-195 Cells by Affinity Chromatography with Either Human Autoantibodies to TPO or Autoantibodies to Tg, Respectively.

The data of Figure 4, A and B demonstrate the reduction of IgG binding with immobilized $\mathrm{AE}_{\text {anti TPO }}$ and $\mathrm{AE}_{\text {anti-Tg, }}$ respectively, in the presence of the appropriate thyroid antigens in liquid phase. The reduction is dependent on TPO concentration (Figure 4, A) and $\mathrm{Tg}$ concentration (Figure 4, B). Moreover, the immobilized $\mathrm{AE}_{\text {anti-TPO }}$ and $\mathrm{AE}_{\text {anti-Tg }}$ show similar effects as immobilized TPO and Tg (Figure 4, A and B).

On the whole, the data shown in Figure 4, A prove competition of immobilized $\mathrm{AE}_{\text {anti-TPO }}$ vs. dissolved TPO for binding of the same IgG, viz., anti-TPO. Similarly, the data shown in Figure 4, B prove competition of immobilized $\mathrm{AE}_{\text {anti-Tg }}$ vs. dissolved $\mathrm{Tg}$ for binding of anti-Tg.

\section{Purification of $B P_{\text {anti-TPo }}$ and $B P_{\text {anti-Tg }}$}

$\mathrm{AE}_{\text {anti-TPO }}$ and $\mathrm{AE}_{\text {anti-Tg }}$ (each $5 \mathrm{mg}$ ) were fractionated by size exclusion chromatography on TSK-40 gel with refractometric detection. The elution profiles are shown in Figure 5.
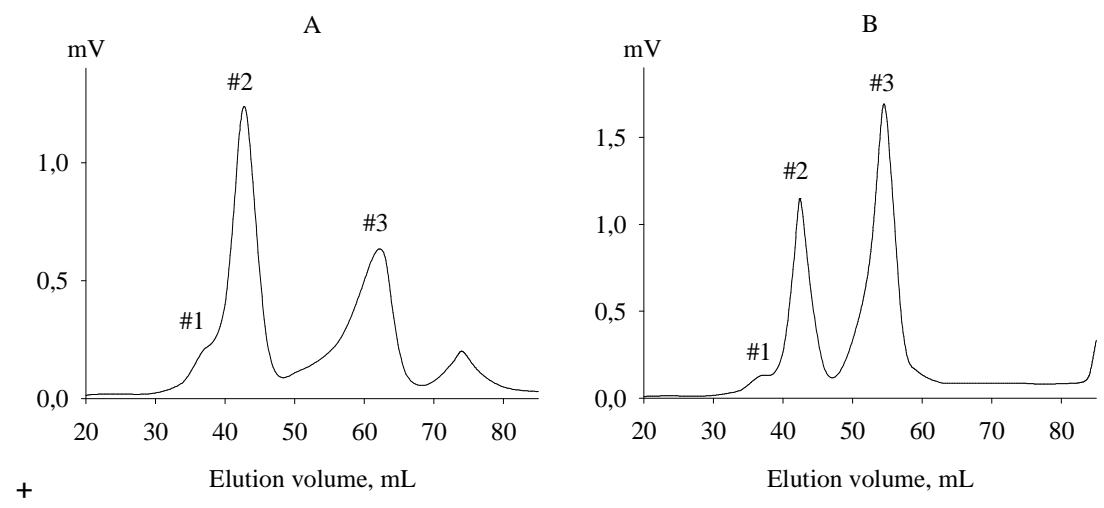

E. P. Kiseleva, K. I. Mikhailopulo, G. I. Novik, E. Szwajcer Dey, E. L. Zdorovenko, A. S. Shashkov and Y. A. Knirel (2014), Research in Immunology: An International Journal, DOI: 10.5171/2014.355367 
Figure 5. Size Exclusion Chromatography of Crude BP anti-TPo $_{(A)}$ and $B_{\text {anti-Tg }}(B)$ on TSK 40 Gel (60 x $1.6 \mathrm{~cm})$. The Elution Profiles were Detected by Differencial Refractometer. Fractions \#2 and \#3 of Each BP were Used for NMR Spectroscopy. Abbreviations: $\mathrm{BP}_{\text {anti-TPo }}$ and $\mathrm{BP}_{\text {anti-Tg }}$ - The Yeast Biopolymers that Selectively Bind Human Autoantibodies to Thyroid Peroxidase and Thyroglobulin.

The elution profile of $\mathrm{AE}_{\text {anti-TPO }}$ contained 4 peaks (Figure 5, A). The first and last peaks corresponded to bad volume and low molecular weight contaminations, respectively; they were not collected. Other peaks were collected as fractions $\mathrm{BP}_{\text {anti-TPO- }}$ 2 and $\mathrm{BP}_{\text {anti-TPO}}-3$ corresponding to molecular weights $5000-7000 \mathrm{Da}$ and 1000 - $1500 \mathrm{Da}$, respectively.

The elution profile of $\mathrm{AE}_{\text {anti-Tg }}$ had a similar form (Figure 5, B), though the retention times of peaks \#3 in Figures 5, A and 5, B were inconsistent; the second and third peaks were collected as fractions $\mathrm{BP}_{\text {anti-Tg }}-2$ and $\mathrm{BP}_{\text {anti-Tg }}-3$.

All collected fractions contained BPs in quantities that were sufficient for NMR spectroscopy $(2.75 \mathrm{mg}, 1.5 \mathrm{mg}, 2.15 \mathrm{mg}$ and $2.3 \mathrm{mg}$ for $\mathrm{BP}_{\text {anti-TPO-2, }} \mathrm{BP}_{\text {anti-TPO}}-3$, $\mathrm{BP}_{\text {anti- } \mathrm{Tg}}-2$ and $\mathrm{BP}_{\text {anti-Tg }}-3$, respectively).
NMR Spectroscopy of $B P_{\text {anti-TPo }}$ and
BP $_{\text {anti-Tg }}$

Structure of BPs contained in fractions $\mathrm{BP}_{\text {anti-TPO}}-2, \quad \mathrm{BP}_{\text {anti-TPO}}-3, \quad \mathrm{BP}_{\text {anti-Tg }}-2$ and $\mathrm{BP}_{\text {anti-Tg }}-3$ was analyzed by NMR spectroscopy. ${ }^{1} \mathrm{H}$ NMR spectra of $\mathrm{BP}_{\text {anti-TPO- }}$ 3 and $\mathrm{BP}_{\text {anti-Tg }}-3$ were not interpretabile. Since ${ }^{1} \mathrm{H}$ NMR and ${ }^{13} \mathrm{C}$ NMR spectra of $\mathrm{BP}_{\text {anti-TPO-2 }}$ and $\mathrm{BP}_{\text {anti-Tg}}-2$ were identical, only the data for $\mathrm{BP}_{\text {anti-TPO- }} 2$ are shown in Figure 6 and Table 2 as an example. ${ }^{1} \mathrm{H}$ NMR spectrum of $\mathrm{BP}_{\text {anti-Tg-2 }}$ is shown in Appendix 3. Analysis by two-dimensional NMR spectroscopy, including ${ }^{1} \mathrm{H},{ }^{1} \mathrm{H}$ COSY and ${ }^{1} \mathrm{H},{ }^{13} \mathrm{C}$ HSQC experiments, indicated that the BPs contained in fractions $\mathrm{BP}_{\text {anti-TPO}}-2$ and $\mathrm{BP}_{\text {anti-Tg }}-2$ are linear $\alpha-1,6$ glucans.

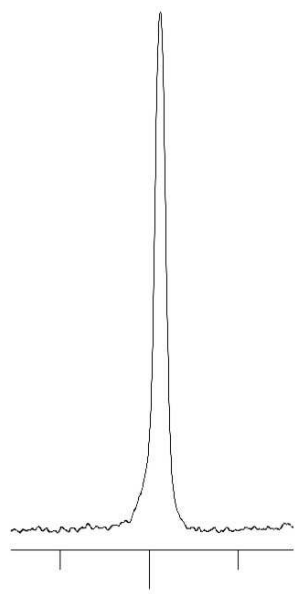

5.00

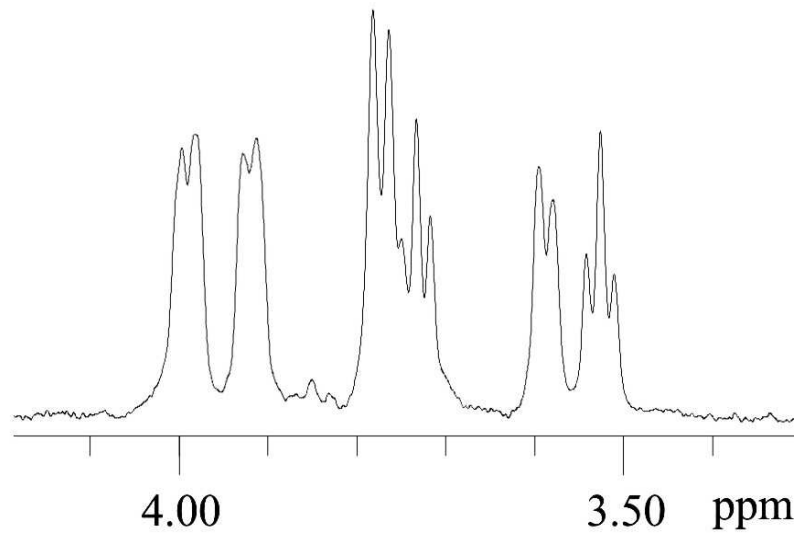

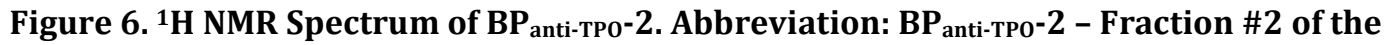
Yeast Biopolymers that Selectively Bind Human Autoantibodies to Thyroid Peroxidase and were Isolated by Affinity Chromatography with the Antibodies.

Table 2. ${ }^{1} \mathrm{H}$ NMR Data of the $\mathrm{BP}_{\text {anti-TPO}}-2(\delta, \mathrm{ppm})$. Abbreviation: $\mathrm{BP}_{\text {anti-TPO}}-2$ - Fraction \#2 of the Yeast Biopolymers that Selectively Bind Human Autoantibodies to Thyroid Peroxidase. 


\begin{tabular}{|l|l|l|l|l|l|}
\hline H-1 & H-2 & H-3 & H-4 & H-5 & H-6a, $\mathbf{6 b}$ \\
\hline 4.99 & 3.59 & 3.73 & 3.53 & 3.92 & $3.77,3.99$ \\
\hline
\end{tabular}

\section{Confirmation of $B P_{\text {anti-TPo }}$ and $B P_{\text {anti-Tg }}$ Functional Activity}

To confirm the suggestion that $\mathrm{BP}_{\text {anti-TPO- }} 2$ actually contain $\mathrm{BP}_{\text {anti-TPO, ELISA test was }}$ performed. $\mathrm{BP}_{\text {anti-TPO-2, TPO as a positive }}$ control and protein A from Staphyllococcus aureus as a negative control were immobilized on microplates and incubated with either pure anti-TPO or pure total human Igs (without anti-TPO and anti-Tg) (ELISA, test 5). The data are shown in
Figure 7. The data confirm the presence of $\mathrm{BP}_{\text {anti-TPO }}$ in the fraction.

To confirm the suggestion that $\mathrm{BP}_{\text {anti-Tg }}-2$ actually contains $\mathrm{BP}_{\text {anti-Tg, ELISA test was }}$ performed in a similar way; Tg and pure anti-Tg were used instead of TPO and pure anti-TPO, respectively (ELISA, test 6). The data are shown in Figure 8. The data confirm the presence of $\mathrm{BP}_{\text {anti-Tg }}$ in the fraction.
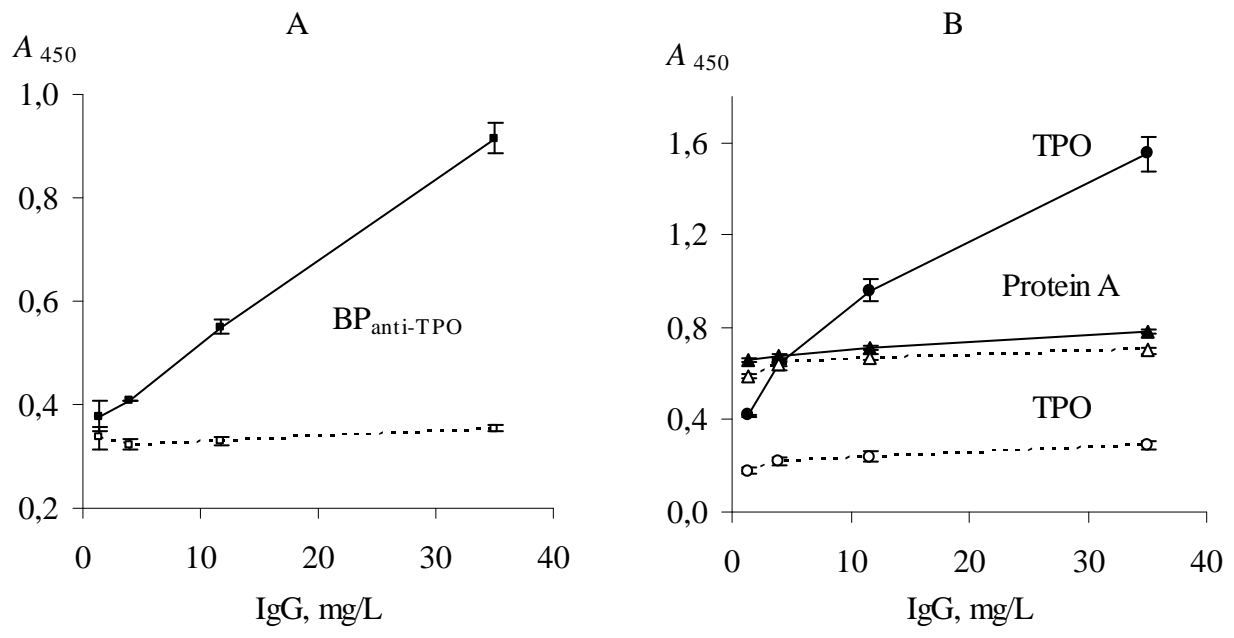

Figure 7. Interaction of Pure Anti-TPO (Black Symbols, Solid Lines) and Pure Total IgG

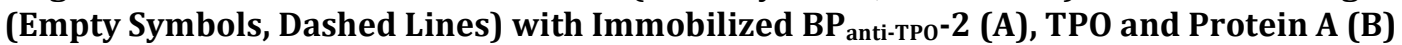

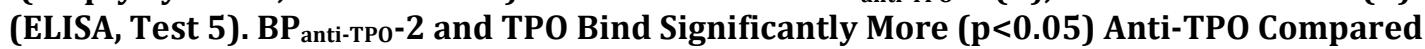
to Total IgG (Control). Representative Data from Three Independent Experiments are Shown. Values are Means \pm Range for Duplicate Wells. Abbreviations: TPO - Thyroid

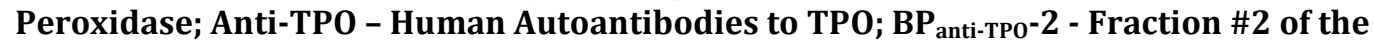




\section{Yeast Biopolymers that Selectively Bind Anti-TPO and were Isolated by Affinity} Chromatography with the Antibodies.

A

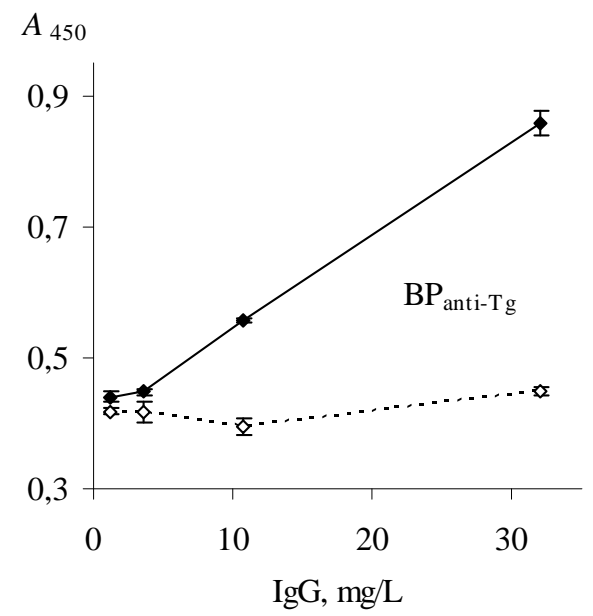

B

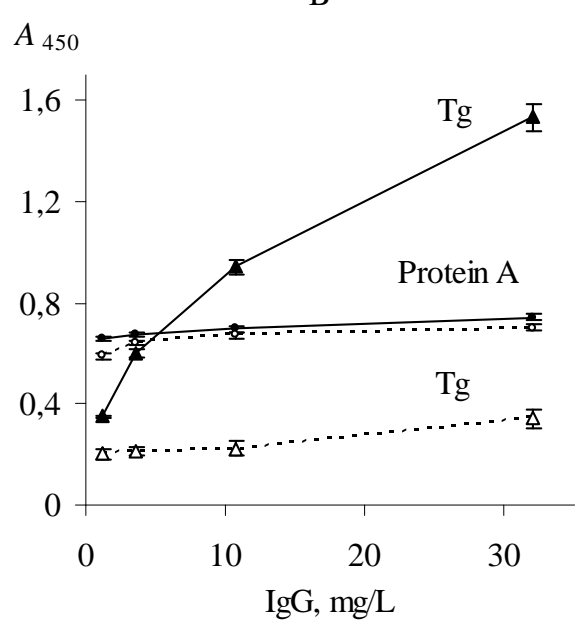

Figure 8. Interaction of Pure Anti-Tg (Black Symbols, Solid Lines) and Pure Total IgG

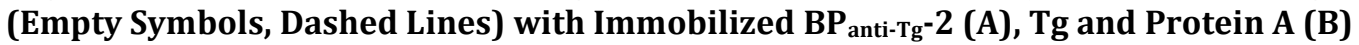
(ELISA, Test 6). $\mathrm{BP}_{\mathrm{anti}-\mathrm{Tg}}-2$ and Tg Bind Significantly More $(\mathrm{p}<0.05)$ Anti-Tg Compared to

Total IgG (Control). Representative Data from Three Independent Experiments are Shown. Values are Means \pm Range for Duplicate Wells. Abbreviations: Tg - Thyroglobulin;

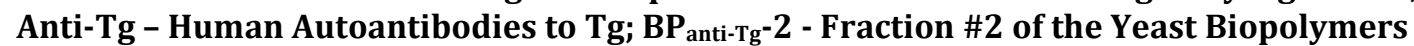
that Selectively Bind Human Autoantibodies to Tg and were Isolated by Affinity Chromatography with the Antibodies.

\section{Discussion}

CFF of S. cerevisiae BIM Y-195 as Source of $B P_{\text {anti-TPo }}$ and $B P_{\text {anti-Tg }}$ and Affinity Chromatograpty as Biospecific Method for Isolation of Both BPs are Suitable

We used selected strains of $S$. cerevisiae and $D$. hansenii since these yeasts are consumed generally with traditional foods (Andrade et al., 2010; Cano-García et al., 2013; Gori et al., 2012; Sibirny and Voronovsky, 2009; Wszolek et al., 2006). Moreover, whole cells, compounds and substances of $S$. cerevisiae are used as nutritional supplements, food additives and pharmaceutics with immunomodulatory properties, respectively (Petravić-Tominac et al., 2011; Jawhara et al., 2012). Similaty to widely used $S$. cerevisiae, $D$. hansenii was found to have enormous biotechnological potential in agro-food sector (Breuer and Harms,
2006; Vetriselvi et al., 2010). In addition, both yeasts are implicated in immunomodulation (Generoso et al., 2010; Martins et al., 2009; Reyes-Becerril et al., 2012). Moreover, S. cerevisiae strains share bio-therapeutic properties with well known probiotic $S$. cerevisiae var. boulardii (Izadnia et al., 1998; Jahn et al., 1996; Van der Aa Kühle et al., 2005).

In present study, we show that $\mathrm{CFF}$ and $\mathrm{CF}$ of $S$. cerevisiae BIM Y-195 contain BP anti-TPO and $\mathrm{BP}_{\text {anti-Tg }}$ as opposed to cell fractions of D. hansenii BIM Y-4 (Table 1).

Enzymatic digestion with either thermal treatment (Núñez et al., 2006) or chemical extraction (Huang and Li, 2012; Pitarch et al., 2008) as well as chemical extraction itself (Klis et al., 2007; Huang, 2008; Zhang et al., 2011) are used traditionally for isolation of yeast cell wall polysaccharides and proteins. The procedures potentially 
are capable of alter/disturb conformation and immunochemical properties of yeast biopolymers. As opposed to CF, CFF-Sc does not require additional treatment. In addition, CFF-Sc demonstrates higher correlation coefficients with $\mathrm{TPO} / \mathrm{Tg}$ in ELISA tests as compared with CF-Sc (Table 1) and therefore it was selected as most preferable source of BPs. The additional testing of CFF-Sc allows proving more convincingly that the cell fraction actually contains BPs (Figure 1).

We used biospecific affinity chromatography on immobilized anti-TPO and anti-Tg to isolate $\mathrm{BP}_{\text {anti-TPO }}$ and $\mathrm{BP}_{\text {anti-Tg, }}$ respectively, from CFF of $S$. cerevisiae BIM Y-195, just as it was done early for isolation of BPs from CFF of B. bifidum BIM B-733D (Kiseleva et al., 2013). The combined data of Figure 2 and 3 prove unambiguously that $\mathrm{AE}_{\text {anti-TPO }}$ contains $\mathrm{BP}_{\text {anti-TPo }}$ and $\mathrm{AE}_{\text {anti-Tg }}$ contains $\mathrm{BP}_{\text {anti-Tg. Thus, biospecific affinity }}$ chromatography allows us to isolate crude $\mathrm{BP}_{\text {anti-TPo }}$ and $\mathrm{BP}_{\text {anti-Tg. }}$

\section{The BP anti-TPo and $\mathrm{BP}_{\text {anti-Tg }}$ are Linear $\alpha-1$, 6-glucans}

To pure isolated $\mathrm{BP}_{\text {anti-TPo }}$ and $\mathrm{BP}_{\text {anti-Tg, we }}$ fractionated $\mathrm{AE}_{\text {anti-TPO }}$ and $\mathrm{AE}_{\text {anti-Tg }}$ by size exclusion chromatography (Figures 4 and $5)$. The data of ${ }^{1} \mathrm{H}$ NMR spectroscopy (Figure 6, Table 2, Appendix 3) prove that fractions \#2 of both AEs contain identical substance, viz., linear $\alpha$-1, 6-glucan with 5$7 \mathrm{kDa}$ molecular weight.

The data of ELISA (Figure 7) prove that fraction \#2 of $\mathrm{AE}_{\text {anti-TPO demonstrates }}$ functional activity characteristic of $\mathrm{BP}_{\text {anti- }}$ TPO, viz., ability to interact selectively with anti-TPO. Similarly, fraction \#2 of $\mathrm{AE}_{\text {anti-Tg }}$ demonstrates ability to interact selectively with anti-Tg (Figure 8). Thus, $\mathrm{BP}_{\text {anti-TPO }}$ and $\mathrm{BP}_{\mathrm{anti}} \mathrm{Tg}$ have identical structure and are linear $\alpha$-1, 6-glucans.

Interestingly, that size exclusion chromatography profiles (Figures 4 and 5) show sharp and symmetrical peaks related to $\alpha-1$, 6-glucan, whereas other studies generally demonstrate broad and assymetrical elution peaks of bacterial/yeast dextrans (Moussa et al,
2012; Sarwat et al, 2008), at that average molecular weight of bacterial/yeast dextrans are significantly higher that in our study. Moreover, small peaks in bad volume (Figures 4 and 5) suggest that both AEs contained almost no substances with molecular weights over $7 \mathrm{kDa}$. Therefore, we assume that either $S$. cerevisiae BIM Y195 does not produce high-molecular weigth linear $\alpha-1,6$-glucan or we do not isolate such $\alpha-1,6$-glucan by biospecific chromatograpty since it does not have activity characteristic of $\mathrm{BP}_{\text {anti-TPo }}$ and $\mathrm{BP}_{\text {anti-Tg. }}$

We unexpectedly show that the structure of both BPs is identitical, which is in accord with (i) the presence of common B cell and T cell epitopes shared between TPO and Tg (Hoshioka et al, 1994; Kohno et al, 1988; McLachlan and Rapoport, 1989) and (ii) the existence of the circulating autoantibodies with dual specificity for $\mathrm{Tg}$ and TPO that were detected in the serum of rabbits immunized with $\mathrm{Tg}$ and commonly present in serum of peoples diagnosed with HT (Estienne et al., 1999; Ruf et al, 1994; Thrasyvoulides and Lymberi, 2004). Unfortunately, common B cell epitopes shared between TPO and Tg were not identified up to date, probably, due their conformational or/and cryptic nature or because of their production through the mechanism of epitope spreading. The mechanism was proven in the study (Thrasyvoulides and Lymberi, 2004), in which rabbits immunized with selected $\mathrm{Tg}$ peptide produced bispecific antibodies interacting with sites of $\mathrm{Tg}$ not coinciding with the peptide sequence of the immunogen.

One more unexpected finding is that $\mathrm{BP}_{\text {anti- }}$ TPO and $\mathrm{BP}_{\text {anti-Tg }}$ are carbohydrates. Taking into account that TPO and $\mathrm{Tg}$ are glycoproteins, one could assume that $\alpha-1$, 6-glucan competes for anti-TPO (anti-Tg) binding with carbohydrate chains of TPO (Tg). The known data suggest that the carbohydrate chains of TPO do not contribute to TPO recognition by anti-TPO (Foti and Rapoport, 1990; Giraud et al., 1992; Kiso et al., 1992; Moura et al., 1991). On the contrary, improved glycosylation of $\mathrm{Tg}$ weakens interaction of the thyroid 
antigen with anti-Tg due to distorting conformation of the polypeptide chain or masking its antigenic regions (Fenouillet, et al., 1986). Thus, our data suggest immunological similarity of $\alpha-1,6$-glucan and epitopes of TPO (Tg) polypeptide chain. The conclusion is in accordance with known studies (Alekseev et al., 2010; GotoTamura et al., 1976; Miyazaki et al., 1982; Ochi et al., 1982; Perrotti et al., 1986) where detection of cross-reactivity of antibodies against antigen 1 with unrelated antigen 2 was interpreted as immunologic similarity between these antigens.

Third unpredictable result is identity between BPs isolated from CFF-Sc in present study and BPs isolated recently from CFF of $B$. bifidum BIM B-733D (Kiseleva et al., 2013).

\section{Carbohydrates as Peptidomimetics}

Molecular mimicry, in the broad sense, is structural, functional or immunologic similarities between unrelated macromolecules (Oldstone, 1998). The carbohydrate nature of both BPs is in accord with the known cases of the immunological similarity between peptide and carbohydrate (Agadjanyan et al, 1997; Guilherme et al, 2006; Heimburg-Molinaro et al, 2009; Luo et al., 1998; Luo et al., 2000). Generally, the cases of molecular mimicry between protein and non-protein are rare and as a rule do not relate to autoimmunity. In our perusal of the literature on bacterial/viral triggering of autoimmunity via molecular mimicry mechanism, we found only one carbohydrate, viz., streptococcal group A epitope, N-acetyl glucosamine, that structurally mimic cardiac protein myosin in human rheumatic carditis. On the contrary, molecular mimicry between bacterial/viral proteins and human protein antigens implicated in autoimmune disease pathogenesis is well known and most proven mechanism of autoimmune disease triggering (Atkinson et al., 1994; Cunningham, 2000; Dale and Beachey, 1985; Gautam et al., 1998; KatonaDurekovic, 2007; Root-Bernstein et al., 2009).
Recently, we show for the first time immunological similarity between $\alpha-1$, 6glucan isolated from CFF of probiotic bacterium $B$. bifidum BIM B-733D and thyroid proteins, TPO and Tg, implicated in ATD pathogenesis (Kiseleva et al., 2013). In the present study, we extended the list of commensals producing substances with the same properties. We take into account that $\alpha-1,6$-glucans are quite different from the glucans with other glycoside linkages because they have many possible conformations due to flexibility of 1-6 linkage (Zhang et al., 2007) that give an possible explanation for unusual property of the glycopolymer, e.g. ability to crossreact with anti-TPO and anti-Tg, thus mimicking natural thyroid proteins, TPO and $\mathrm{Tg}$.

\section{Microorganisms in Triggering/Abrogation of Autoimmune Diseases}

In the experimental models, autoimmune disease occurs only in susceptible strains, under particular environmental conditions, and with the usage of adjuvant molecules (Pordeus et al., 2008). In humans, any autoimmune disease can and does occur only in genetically predisposed persons. They have a population of self-reactive $\mathrm{T}$ cells that are potentially intolerant but under special circumstances able to react with the host's antigens. One of the most common "special circumstances" is infectious agents that can induce or accelerate pre-existing autoimmune responses (Harkiolaki et al., 2009; Kohm et al., 2003; Roep, 2003; Wegner et al., 2009).

Interestingly, well known infection agents may protect from autoimmunity or even abrogate an ongoing autoimmune process (Gaisford et al., 2009; Kivity et al., 2009; Sfriso et al., 2010). Moreover, the same microorganism may induce one autoimmune disease and protect from another one. For example, Epstein-Barr virus can induce systemic lupus erythematosus and protect from type 1 diabetes mellitus (Kivity et al., 2009). Same possible mechanisms of abrogation an ongoing autoimmune process and 
protection from autoimmunity are proposed to date (Sfriso et al., 2010). For example, infection at another location might keep autoaggressive cells from reaching the site of autoimmune destruction. In addition, several pathogens can shift the $\mathrm{T}$ cells balance toward a more immunosuppressive state, where Tregs might be induced. It may have therapeutic benefits for patients suffering from Th1/Th17-mediated autoimmune diseases (in particular, HT) (Phenekos et al., 2004; Qin et al., 2012). The last-named mechanism is triggered by ligands of pathogen-associated molecular patterns receptors expressed on/into antigenpresenting immune cells (Den Dunnen et al., 2010; Jeong and Lee, 2011; Kawai and Akira, 2009; Zeuthen et al., 2008). Since the ligans are shared between pathogens and commensals/probiotics (Didierlaurent et al., 2006; Rumbo et al, 2006), beneficial microorganisms can trigger/prevent autoimmunily just it certain pathogens do.

Our recent findings (Kiseleva et al., 2013) and the data of present study allow assuming that molecular mimicry per se can work as protective mechanism, which we will duscuss in detail in section 4.6.

\section{Dextrans from Other Microorganisms and Their Immunological Potency (Immunogenicity)}

According the comprehensive enzyme information system BRENDA (www.brenda-enzymes.info), the list of known dextran-producing microorganisms includes bacteria of genera Lactobacillus, Leuconostoc, Streptococcus and Weissella. Recently it was shown that S. cerevisiae NRRL Y-1534 produce secretory dextran with average molecular weight $67 \mathrm{kDa}$ (Moussa and Khalil, 2012). The data on numerous applications of the dextrans and derivative substances in food industry and clinical practice suggest that the negative effects of dextrans on human health were not found to date (Liu et al., 2009; Neiser et al., 2011; Qader et al., 2005).

The linear bacterial decstrans are rare. Three known dextrans are the most similar to linear $\alpha-1,6$-glucan obtained in present study. One of them is the water soluble dextran produced by Leuconostoc mesenteroides NRRL B-512, which have a molecular weight of $8 \times 10^{7}$ $\mathrm{Da}$ and contain 95\% linear $\alpha-(1 \rightarrow 6)$ linkages and $5 \% \quad \alpha-(1 \rightarrow 3)$ linkages (Van Cleve et al., 1956); the latter are branch points for side chains including no more than two glucose units. Another one is dextran from Weissella confuse, strains E392 (Maina et al., 2008) and LBAE C39-2 (Amari et al., 2013) that contains only $2.7 \%$ - 2.8\% $\alpha$ - $(1 \rightarrow 3)$-linked branches. The very similar to dextran shown in our study is an unique dextran from an indigenous $\mathrm{Ln}$. mesenteroides CMG713 that contains 100\% $\alpha-(1 \rightarrow 6)$-linked glucopyranosyl units in the main chain and does not have any branching (Sarwat et al., 2008).

It has been shown that dextran-specific antibodies (anti-dextrans) commonly detected in the serum samples of healthy donors are produced as result of immune response to naturally occurring dextrans from caries-inducing Streptococcus species and intestinal bacteria (Neiser et al., 2011; Paul et al., 2009). Antigenic determinants of $\alpha-1,6$-glucans responsible for its specific interaction with human anti-dextrans involve six and perhaps seven glucosyl residues (Cisar et al., 1975). Thus, $\alpha-1,6$ glucan from $S$. cerevisiae BIM Y-195 is sufficiently large to act as an antigen, e.g. bind pre-existing anti-dextrans and crossreact with pre-existing anti-TPO/anti-Tg.

We assume that 5 - $7 \mathrm{kDa} \alpha-1$, 6-glucan from $S$. cerevisiae BIM Y-195 has low immunogenicity, since it was shown that low molecular weight dextrans are appreciably less immunogenic than high molecular weight dextrans (Neiser et al., 2011). However, we can not exclude the presence of immunologically relevant BPs with the same structure but higher molecular weight in the cells of the yeast, which allow us to include antibodies to $\alpha-1$, 6-glucan from $S$. cerevisiae BIM Y-195 in the list of the possible players in ATD pathogenesis. 
$\alpha-1,6-G l u c a n$ and Antibodies to $\alpha-1,6-$ Glucan as Putative Players in ATD Pathogenesis

We discuss the possible role of $\alpha-1,6-$ glucan and antibodies to $\alpha-1,6$-glucan in the molecular mechanisms of the immune response typical of ATD by allowing either negative or positive impact of both substances on human health (triggering/acceleration and prevention/abrogation of ATD, respectively) (Figure 9).

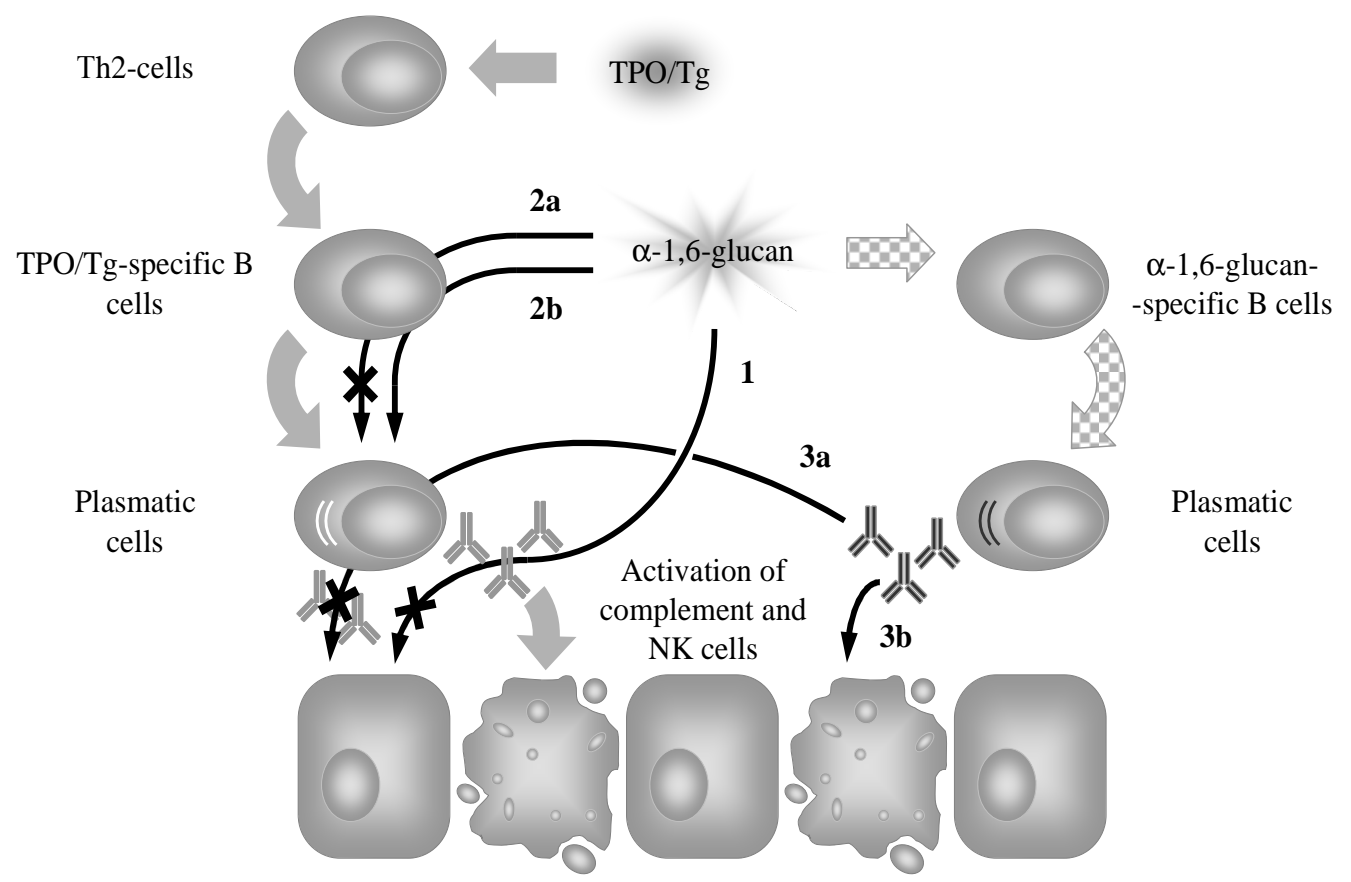

Thyroid cell death

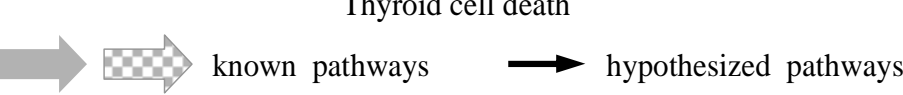

Figure 9. Presumptive Roles of $\alpha-1,6$-Glucan from $S$. cerevisiae BIM Y-195 and Natural Antibodies to $\alpha-1,6-G l u c a n$ in ATD Pathogenesis: A Hypothetical Model. In "Normal" ATD Pathogenesis Anti-TPO and Anti-Tg Interact with TPO and Tg, Respectively, Presented by MHC II/Abnormally Expressed on Basolateral Membrane of Thyroid Cells, which Leads to Thyroid Cell Destruction through Complement Activation and Antibody-Dependent Cell Mediated Cytotoxicity (Green Arrows). Dextran-Specific Antibodies (Anti-Dextrans) are Produced as Result of Immune Response to Naturally Occurring Dextrans from Commensals, Including Yeasts (Chequered Arrows). The $\alpha-1,6-$ Glucan (1) Bind AntiTPO/Anti-Tg and Thereupon Prevents Their Interaction with TPO/Tg; (2) Interacts with TPO/Tg-Specific B Cells Receptors and Thereupon Either (2a) Blocks the B Cells as an Antagonist or (2b) Activates the B Cells as an Agonist. Natural Antibodies to $\alpha$-1, 6-Glucan Either (3a) Reduce Anti-TPO/Anti-Tg Synthesis via Feedback Mechanism or (3b) Act Similarly to Anti-TPO/Anti-Tg. Thus, $\alpha-1,6$-Glucan and Natural Antibodies to $\alpha-1,6$ Glucan Either Induce/Accelerate ATD (1, 2a, 3a; Black Arrows) or Prevent/Abrogate ATD through a Mechanism of Molecular Mimicry (2b, 3b; 1, 2a, 3a; Crossed out Black Arrows). Abbreviations: Tg - Thyroglobulin; TPO - Thyroid Peroxidase; NK Cells - Natural Killer Cells; Th2 - T Helper Cells of Class 2. 
Firstly, we assume that $\alpha$-1, 6-glucan is able to bind pre-existing serum anti-TPO (antiTg) (Figure 9, 1). If it is true, $\alpha-1,6$-glucan prevents interaction of anti-TPO (anti-Tg) with either TPO (Tg) presented by MHC II (Salmaso et al., 2002; Weetman, 1997; Weetman, 2003) or TPO abnormally expressed on basolateral membrane of thyroid cells (Zimmer et al., 1997). Thus, $\alpha$ 1, 6-glucan can reduce thyroid cell destruction that in "normal" ATD pathogenesis occur through complement activation (Chiovato et al., 1993; Potluková and Limanová, 2007) or antibodydependent cell mediated cytotoxicity (Rebuffat et al., 2008).

Secondly, $\alpha$-1, 6-glucan, T cell independent antigen of class 2 (Mond et al., 1995), can interact with the receptors of $\mathrm{B}$ cells specific to TPO and Tg, since these receptors are identical to secreted forms (anti-TPO and anti-Tg) with the exception of the presence of an integral membrane domain (Kindt et al., 2007). To discuss this point in details, we take into account that polyspecificity is commonly recognized intrinsic property of $B$ cell receptor recognition (Wucherpfennig et al., 2007) though the data on the role of the so called "altered ligand" (e.g., partial homolog of the natural ligand, in our case TPO and Tg) in B cell receptor recognition are limited (Kouskoff et al., 1998; Liu et al., 2010; Wucherpfennig et al., 2007). Additionally, we take into account that the strength of signaling via the B cell receptor controls B cell fate in immunity and autoimmunity (Noelle et al., 2005), and in the immune response induced by $\mathrm{T}$ cell independent antigen of class 2 large differences in affinity (in our case, the differences in affinity of thyroid antigens and $\alpha-1$, 6glucan to receptors of thyroid antigensspecific B cells) produce only small differences in the intrinsic ability of B cells to respond to antigen (Shih et al., 2002). It is possibly that $\alpha-1,6$-glucan induce the same effect as natural thyroid antigens (negative impact on health) (Figure 9, 2b). Alternatively, we assume that it block thyroid antigens-specific B cells proliferation and synthesis of antibodies to thyroid antigens (positive impact on health) (Figure 9, 2a). Additionally, we do not exclude that cross-reaction of $\alpha-1,6$ glucan with receptors of $B$ cells specific to thyroid antigens is irrelevant to ATD.

At last, we take into account the possible role of antibodies to $\alpha-1,6$-glucan. Since $\alpha$ 1 , 6-glucan mimic thyroid antigens, antibodies to $\alpha-1,6$-glucan can mimic antiTPO and anti-Tg and either ( $i$ ) induce the same effects as anti-TPO and anti-Tg including complement activation or antibody-dependent cell mediated cytotoxicity (negative impact on health) (Figure 9, 3b), or (ii) induce feedback inhibition of TPO-specific and Tg-specific B cells (positive impact on health) (Figure 9, $3 \mathrm{a})$. It is known that some clones of anti-Tg are able to inhibit $\mathrm{T}$-cell proliferative response and $\mathrm{T}$ cell cytotoxicity against thyroid cells and thus ameliorate ATD either via sequestration of antigenic epitopes of Tg or via blockade of peptideMHC complexes (Dai et al., 2005; Salamero et al., 1987). The antibodies to $\alpha-1,6$ glucan may prevent or ameliorate ATD in a similar way. Additionally, we do not exclude that antibodies to $\alpha$-1, 6-glucan do not mimic anti-TPO and anti-Tg and the effect of antibodies to $\alpha-1,6$-glucan is irrelevant to ATD.

Noteworthy that we take into account only those of the known mechanisms of autoimmune destruction of thyroid cells and thyroid autoimmunity in whole (Blanchin et al., 2003; Londei et al., 1985; MacKenzie et al., 1987; Stassi and De Maria, 2002) which are relevant to the possible targets of either $\alpha-1,6$-glucan or antibodies to $\alpha-1$, 6-glucan, viz., anti-TPO/anti$\mathrm{Tg} /$ receptors of thyroid antigen-specific $\mathrm{B}$ cells and TPO/Tg, respectively.

It is importantly that immunologic similarity of thyroid antigens and $\alpha-1,6$ glucan from S. cerevisiae BIM Y-195 and other human symbionts (Kiseleva et al., 2013) is necessary but not sufficient prerequisite for triggering/acceleration or prevention/abrogation of autoimmune disease (in our case, ATD) by molecular mimicry mechanism, as it was accentuated in known review of Oldstone $M$. B. (Oldstone, 2005). The main requirements are hypothesized to be (i) genetic 
predisposition to ATD (Muixi et al., 2008) and (ii) intestinal epithelium penetration by $\alpha-1,6$-glucan.

\section{Conclusion}

In this paper, we show that Saccharomyces cerevisiae BIM Y-195 (but not Debaryomyces hansenii BIM Y-4) contains BPs with unusual immunochemical property, notably ability to distinguish anti-TPO (anti-Tg) from other IgG and compete with TPO (Tg) for binding of antiTPO (anti-Tg) in ELISA tests. The BPs, viz., $\mathrm{BP}_{\text {anti-TPO }}$ and $\mathrm{BP}_{\text {anti-Tg, }}$ were isolated, purified and identified as linear $\alpha-1,6-$ glucans. The unusual immunochemical property of $\mathrm{BP}_{\text {anti-TPO }}$ and $\mathrm{BP}_{\text {anti-Tg }}$ suggests that they cross-react with anti-TPO and anti-Tg, respectively, which in turn points to immunological similarity between $\mathrm{BP}_{\text {anti- }}$ TPO and epitopes of TPO and between $\mathrm{BP}_{\text {anti-Tg }}$ and epitopes of Tg. Since both BPs have identical chemical structure, we assume that each BP immunologically mimic common epitopes shared between TPO and Tg and binds autoantibodies with dual specificity to TPO and Tg.

Thus, it was shown for the first time an immunological similarity (molecular mimicry) of $\alpha-1$, 6-glucans of $S$. cerevisiae BIM Y-195 and human thyroid proteins, TPO and Tg. Our data point to a possible role of wine yeast in the molecular mechanisms of the immune response typical of ATD, which we discussed in this paper allowing for both negative and positive impact of yeast $\alpha$-1, 6-glucans on human health (triggering/acceleration and prevention/abrogation of ATD, respectively).

The data obtained and known mechanisms of ATD pathogenesis are insufficient to draw conclusions in context of human health. It appears to be advisable to extend this study by using of animal models and clinical trials to investigate whether $\alpha-1,6$ glucan from $S$. cerevisiae is a possible candidate for antigen-specific immunosuppressive therapy against ATD or, alternatively, recommend limiting the consumption of tradicional foods, food additives and pharmaceutics containing cells/components of the yeast in order to avoid triggering/acceleration of ATD.

\section{Acknowledgments}

This work was supported by the Belarusian Republican Foundation for Fundamental Research (grant X10P-130), Russian Foundation for Basic Research (grant RFBR-BEL_A No. 10-04-90047) and VISBY (grant 00474/2010).

\section{References}

Agadjanyan, M., Luo, P., Westerink, M. A. J., Carey, L. A., Hutchins, W., Steplewski, Z., Weiner, D. B. \& Kieber-Emmons, T. (1997). "Peptide Mimicry of Carbohydrate Epitopes on Human Immunodeficiency Virus," Nature Biotechnology, 15 (6) 547 - 551.

Al-Zarzour, N. \& Monem, F. (2011). “Are Human Herpes Viruses Associated with Autoimmune Thyroid Disease?," Journal of Infection in Developing Countries, 5 (12) 890-892.

Alberti, G. (2001). "Noncommunicable Diseases: Tomorrow's Pandemics," Bulletin of the World Health Organization, 79 (10) 907.

Alekseev, V. Y., Kaboev, O. K., Shcherbakova, O. G., Semenova, E. V. \& Filatov M. V. (2010). "Immunological Similarity of Diphtheria Toxin and EGF Receptor," Tsitologiia, 52 (5) 364-370. (Article in Russian).

Amari, M., Arango, L. F., Gabriel, V., Robert, H., Morel, S., Moulis, C., Gabriel, B., RemaudSiméon, M., Fontagné-Faucher, C. (2013). "Characterization of a Novel Dextransucrase from Weissella Confusa Isolated from Sourdough," Applied Microbiology and Biotechnology, 97 (12) 5413-5422.

Andrade, M. J., Córdoba, J. J., Casado, E. M., Córdoba, M. G. \& Rodríguez, M. (2010). "Effect of Selected Strains of Debaryomyces Hansenii on the Volatile Compound Production of Dry Fermented Sausage "Salchichón," Meat Science, 85 (2) 256-264. 
Anonymous (1976). 'Affinity Chromatography,' Principles and Methods, Pharmacia Fine Chemicals, Uppsala, Sweden, vol. 3, 8-15.

Ashorn, S., Raukola, H., Välineva, T., Ashorn, M., Wei, B., Braun, J., Rantala, I., Kaukinen, K., Luukkaala, T., Collin, P., Mäki, M. \& Iltanen, S. (2008). "Elevated Serum AntiSaccharomyces Cerevisiae, Anti-I2 and Anti-OmpW Antibody Levels in Patients with Suspicion of Celiac Disease," Journal of Clinical Immunology, 28 (5) 486-494.

Atkinson, M. A., Bowman, M. A., Campbell, L., Darrow, B. L., Kaufman, D. L. \& Maclaren, N. K. (1994). "Cellular Immunity to a Determinant Common to Glutamate Decarboxylase and Coxsackie Virus in Insulin-Dependent Diabetes," The Journal of Clinical Investigation, 94 (5) 2125-2129. Beever, K., Bradbury, J., Phillips, D., McLachlan, S. M., Pegg, C., Goral, A., Overbeck, W., Feifel, G. \& Smith, B. R. (1989). "Highly Sensitive Assays of Autoantibodies to Thyroglobulin and to Thyroid Peroxidase," Clinical Chemistry, 35 (9) 1949-1954.

Benvenga, S., Santarpia, L., Trimarchi, F. \& Guarneri, F. (2006). "Human Thyroid Autoantigens and Proteins of Yersinia and Borrelia Share Amino Acid Sequence Homology that Includes Binding Motifs to HLA-DR Molecules and T-Cell Receptor," Thyroid, 16 (3) 225-236.

Blanchin, S., Estienne, V., Durand-Gorde, J. M., Carayon, P. \& Ruf, J. (2003). "Complement Activation by Direct C4 Binding to Thyroperoxidase in Hashimoto's Thyroiditis," Endocrinology, 144 (12) 54225429.

Breuer, U. \& Harms, H. (2006). "Debaryomyces Hansenii - An Extremophilic Yeast with Biotechnological Potencial," Yeast, 23 (6) 415-437.

Bruewer, M., Luegering, A., Kucharzik, T., Parkos, C. A., Madara, J. L., Hopkins, A. M. \& Nusrat, A. (2003). "Proinflammatory Cytokines Disrupt Epithelial Barrier Function by Apoptosis-Independent
Mechanisms," The Journal of Immunology, 171 (11) 6164-6172.

Burek, C. L. \& Talor, M. V. (2009). "Environmental Triggers of Autoimmune Thyroiditis," Journal of Autoimmunity 33 (3-4) 183-189.

Canaris, G. J., Manowitz, N. R., Mayor, G. \& Ridgway, E. C. (2000). "The Colorado Thyroid Disease Prevalence Study," The Archives of Internal Medicine, 160 (4) 526534.

Cano-García, L., Flores, M. \& Belloch, C. (2013). "Molecular Characterization and Aromatic Potential of Debaryomyces Hansenii Strains Isolated from Naturally Fermented Sausages," Food Research International, 52 (1) 42-49.

Caturegli, P., Kuppers, R. C., Mariotti, S., Burek, C. L., Pinchera, A., Ladenson P. W. \& Rose, N. R. (1994). "IgG Subclass Distribution of Thyroglobulin Antibodies in Patients with Thyroid Disease," Clinical and Experimental Immunology, 98 (3) 464-469.

Chiovato, L., Bassi, P., Santini, F., Mammoli, C., Lapi, P., Carayon, P. \& Pinchera, A. (1993). "Antibodies Producing Complement-Mediated Thyroid Cytotoxicity in Patients with Atrophic or Goitrous Autoimmune Thyroiditis," The Journal of Clinical Endocrinology and Metabolism, 77 (6) 1700-1705.

Cisar, J., Kabat, E. A., Dorner, M. M. \& Liao, J. (1975). "Binding Properties of Immunoglobulin Combining Sites Specific for Terminal or Nonterminal Antigenic Determinants in Dextran," The Journal of Experimental Medicine, 142 (2) 435-459.

Clayburgh, D. R., Shen, L. \& Turner, J. R. (2004). "A Porous Defense: The Leaky Epithelial Barrier in Intestinal Disease," Laboratory Investigation, 84 (3) 282-291.

Cooper, G. S. \& Stroehla, B. C. (2003). "The Epidemiology of Autoimmune Diseases," Autoimmunity Reviews, 2 (3) 119-125.

Cunningham, M. W. (2000). "Pathogenesis of Group A Streptococcal Infections," 
Clinical Microbiology Reviews, 13 (3) 470511.

Czaja, A. J., Shums, Z., Donaldson, P. T. \& Norman, G. L. (2004). "Frequency and Significance of Antibodies to Saccharomyces Cerevisiae in Autoimmune Hepatitis," Digestive Diseases and Sciences, 49 (4) 611-618.

Dai, H., Li, Z., Zhang, Y., Lv, P. \& Gao, X. M. (2009). "Elevated levels of Serum Antibodies against Saccharomyces Cerevisiae Mannan in Patients with Systemic Lupus Erythematosus," Lupus, 18 (12) 1087-1090.

Dai, Y. D., Eliades, P., Carayanniotis, K. A., McCormick, D. J., Kong, Y. M., Magafa, V., Cordopatis, P., Lymberi, P. \& Carayanniotis, G. (2005). "Thyroxine-Binding Antibodies Inhibit T Cell Recognition of a Pathogenic Thyroglobulin Epitope," The Journal of Immunology, 174 (5) 3105-3110.

Dale, J. B. \& Beachey, E. H. (1985). "Multiple, Heart-Cross-Reactive Epitopes of Streptococcal M Proteins," The Journal of Experimental Medicine, 161 (1) 113-122.

Davies, T. F. \& Amino, N. (1993). “A New Classification for Human Autoimmune Thyroid Disease," Thyroid, 3 (4) 331-333.

Davies, T. F. (2008). "Infection and Autoimmune Thyroid Disease," The Journal of Clinical Endocrinology and Metabolism, 93 (3) 674-676.

Den Dunnen, J., Gringhuis, S. I. \& Geijtenbeek, T. B. H. (2010). "Dusting the Sugar Fingerprint: C-Type Lectin Signaling in Adaptive Immunity," Immunology Letters, 128 (1) 12-16.

Desplat-Jégo, S., Johanet, C., Escande, A., Goetz, J., Fabien, N., Olsson, N., Ballot, E., Sarles, J., Baudon, J. J., Grimaud, J. C., Veyrac, M., Chamouard, P. \& Humbel, R. L. (2007). "Update on Anti-Saccharomyces Cerevisiae Antibodies, Anti-Nuclear Associated AntiNeutrophil Antibodies and Antibodies to Exocrine Pancreas Detected by Indirect Immunofluorescence as Biomarkers in Chronic Inflammatory Bowel Diseases:
Results of a Multicenter Study," World Journal of Gastroenterology, 13 (16) 23122318.

Didierlaurent, A., Simonet, M. \& Sirard, J.- C. (2006). "Innate and Acquired Plasticity of the Intestinal Immune System," Cellular and Molecular Life Sciences, 62 (12) 12851287.

Duntas, L. H. (2008). "Environmental Factors and Autoimmune Thyroiditis," Nature Reviews Endocrinology, 4 (8) 454460.

Edwards-Ingram, L., Gitsham, P., Burton, N., Warhurst, G., Clarke, I., Hoyle, D., Oliver, S. G. \& Stateva, L. (2007). "Genotypic and Physiological Characterization of Saccharomyces Boulardii, the Probiotic Strain of Saccharomyces Cerevisiae," Applied and Environmental Microbiology, 73 (8) 2458-2467.

Ercolini, A. M. \& Miller, S. D. (2009). "The Role of Infections in Autoimmune Disease," Clinical and Experimental Immunology, 155 (1) 1-15.

Estienne, V., Duthoit, C., Costanzo, V. D., Lejeune, P. J., Rotondi, M., Kornfeld, S., Finke, R., Lazarus J. H., Feldt-Rasmussen, U., Franke, W. G. , Smyth, P., D'Herbomez M., Conte-Devolx, B., Persani, L., Carella, C., Jourdain, J. R., Izembart, M., Toubert, M. E., Pinchera, A., Weetman, A., Sapin, R., Carayon, P. \& Ruf, J. (1999). "Multicenter Study on TGPO Autoantibody Prevalence in Various Thyroid and Non-Thyroid Diseases; Relationships with Thyroglobulin and Thyroperoxidase Autoantibody Parameters," European Journal of Endocrinology, 141 (6) 563-569.

Fenouillet, F., Fayet, G., Hovsepian, S., Bahraoui, E. M. \& Ronin, C. (1986). "Immunochemical Evidence for a Role of Complex Carbohydrate Chains in Thyroglobulin Antigenicity," The Journal of Biological Chemistry, 261 (32): 1515315158.

Foti, D. \& Rapoport, B. (1990). "Carbohydrate Moieties in Recombinant Human Thyroid Peroxidase: Role in 
Recognition by Antithyroid Peroxidase Antibodies in Hashimoto's Thyroiditis," Endocrinology, 126 (6) 2983-2988.

Fresko, I., Ugurlu, S., Ozbakir, F., Celik, A., Yurdakul, S., Hamuryudan, V. \& Yazici, H. (2005). "Anti-Saccharomyces Cerevisiae Antibodies (ASCA) in Behçet's Syndrome," Clinical and Experimental Rheumatology, 23 (4 Suppl 38) S67-70.

Gaisford, W. \& Cooke, A. (2009). "Can Infections Protect against Autoimmunity?," Current Opinion in Rheumatology, 21 (4) 391-396.

Gallagher, S. R. (2011). "Quantitation of DNA and RNA with Absorption and Fluorescence Spectroscopy," Current Protocols in Molecular Biology, Appendix 3:3D.

Gautam, A. M., Liblau, R., Chelvanayagam, G., Steinman, L. \& Boston, T. (1998). “A Viral Peptide with Limited Homology to a Self Peptide Can Induce Clinical Signs of Experimental Autoimmune Encephalomyelitis," Journal of Immunology, 161 (1) 60-64.

Generoso, S. V., Viana, M., Santos, R., Martins, F. S., Machado, J. A. N., Arantes, R. M. E., Nicoli, J. R., Correia, M. I. T. D. \& Cardoso, V. N. (2010). "Saccharomyces Cerevisiae Strain UFMG 905 Protects against Bacterial Translocation, Preserves Gut Barrier Integrity and Stimulates the Immune System in a Murine Intestinal Obstruction Model," Archives of Microbiology, 192 (6) 477-484.

Getts, M. T. \& Miller, S. D. (2010). "99th Dahlem Conference on Infection, Inflammation and Chronic Inflammatory Disorders: Triggering of Autoimmune Diseases by Infections," Clinical and Experimental Immunology, 160 (1) 15-21.

Giraud, A., Franc, J.- L., Long, Y. \& Ruf, J. (1992). "Effects of Deglycosylation of Human Thyroperoxidase on its Enzymatic Activity and Immunoreactivity," Journal of Endocrinology, 132 (2) 317-323.
Gori, K., Sørensen, L. M., Petersen, M. A., Jespersen, L. \& Arneborg, N. (2012). "Debaryomyces Hansenii Strains Differ in Their Production of Flavor Compounds in a Cheese-Surface Model," MicrobiologyOpen, 1 (2) 161-168.

Goto-Tamura, R., Takesue, Y. \& Takesue, S. (1976). "Immunological Similarity between NADH-Cytochrome b5 Reductase of Erythrocytes and Liver Microsomes," Biochimica et Biophysica Acta (BBA) Bioenergetics, 423 (2) 293-302.

Guilherme, L., Kalil, J. \& Cunningham, M. (2006). "Molecular Mimicry in the Autoimmune Pathogenesis of Rheumatic Heart Disease," Autoimmunity, 39 (1) 3139.

Harkiolaki, M., Holmes, S. L., Svendsen, P., Gregersen, J. W., Jensen, L. T., McMahon, R., Friese, M. A., van Boxel, G., Etzensperger, R., Tzartos, J. S., Kranc, K., Sainsbury, S., Harlos, K., Mellins, E. D., Palace, J., Esiri, M. M., van der Merwe, P. A., Jones, E. Y. \& Fugger, L. (2009). "T Cell-Mediated Autoimmune Disease Due to Low-Affinity Crossreactivity to Common Microbial Peptides," Immunity, 30 (3) 348-357.

Harrer, M., Reinisch, W., Dejaco, C., Kratzer, V., Gmeiner, M., Miehsler, W., Norman, G. L., Gangl, A., Vogelsang, H. (2004). “Do High Serum Levels of Anti-Saccharomyces Cerevisiae Antibodies Result from a Leakiness of the Gut Barrier in Crohn's Disease?" European Journal of Gastroenterology \& Hepatology, 15 (12) 1281-1285.

Heath, G. W. (2009). "Physical Activity Transitions and Chronic Disease," American Journal of Lifestyle Medicine, 3 (1) 27S-31S.

Heimburg-Molinaro, J., Almogren, A., Morey, S., Glinskii, O. V., Roy, R., Wilding, G. E., Cheng, R. P., Glinsky, V. V. \& RittenhouseOlson, K. (2009). "Development, Characterization and Immunotherapeutic Use of Peptide Mimics of the ThomsenFriedenreich Carbohydrate Antigen," Neoplasia, 11 (8) 780-792. 
Hoshioka, A., Kohno, Y. \& Niimi, H. (1994). "Identification and Immunopathogenicity of a Common $\mathrm{T}$ Cell Epitope between Human Thyroglobulin and Human Thyroid Peroxidase," Nippon Rinsho/Japanese Journal of Clinical Medicine, 52 (4) 10631068.

Huang, G. \& Li, J. (2012). "Efficient Preparation of Alkali-Insoluble $(1 \rightarrow 3)-\beta$ D-Glucan," International Journal of Food Sciences and Nutrition, 63 (2) 184-186.

Huang, G. L. (2008). "Extraction of Two Active Polysaccharides from the Yeast Cell Wall," Zeitschrift für Naturforschung C, 63 (11-12) 919-921.

Huang, H., Ostroff, G. R., Lee, C. K., Wang, J. P., Specht, C. A. \& Levitz, S. M. (2009). "Distinct Patterns of Dendritic Cell Cytokine Release Stimulated by Fungal $\beta$ Glucans and Toll-Like Receptor Agonists," Infection and immunity, 77 (5) 1774-1781.

Izadnia, F., Wong, C. T. \& Kochoshis, S. A. (1998). "Brewer's Yeast and Saccharomyces Boulardii both Attenuate Clostridium Difficile-Induced Colonic Secretion in the Rat," Digestive Diseases and Sciences, 43 (9) 2055-2060.

Jahn, H.- U., Ullrich, R., Scheneider, T., Lichr, R.- M., Schieferdecker, H. L., Holst, H. \& Zeitz, M. (1996). "Immunological and Tropical Effect of Saccharomyces Cesevisciae and Saccharomyces Boulardii on the Small Intestine in Healthy Human Volunteers," Digestion, 57 (2) 95-104.

Jawhara, S., Habib, K., Maggiotto, F., Pignede, G., Vandekerckove, P., Maes, E, Dubuquoy, L., Fontaine, T., Guerardel, Y. \& Poulain, D. (2012). "Modulation of Intestinal Inflammation by Yeasts and Cell Wall Extracts: Strain Dependence and Unexpected Anti-Inflammatory Role of Glucan Fractions," PLoS One, 7 (7) e40648.

Jeong, E. \& Lee, J. Y. (2011). "Intrinsic and Extrinsic Regulation of Innate Immune Receptors," The Yonsei Medical Journal, 52 (3) 379-392.
Katona-Durekovic, A. (2007). "The Role of Virus Infections in the Pathogenesis of Type 1 Diabetes - A Case Report," Medicinski pregled, 60 (7-8) 397-400.

Kawai, T. \& Akira, S. (2009). "The Roles of TLRs, RLRs and NLRs in Pathogen Recognition," International Immunology, 21 (4) 317-337.

Kelesidis, T. \& Pothoulakis, C. (2012). "Efficacy and Safety of the Probiotic Saccharomyces Boulardii for the Prevention and Therapy of Gastrointestinal Disorders," Therapeutic Advances in Gastroenterology, 5 (2) 111-125.

Kelly, E. K., Wang, L., \& Ivashkiv, L. B. (2010). "Calcium-Activated Pathways and Oxidative Burst Mediate Zymosan-Induced Signaling and IL-10 Production in Human Macrophages," The Journal of Immunology, 184 (10) 5545-5552.

Kindt, T. J., Goldsby, R. A., Osborne, B. A. \& Kuby, J. (2007). 'Kuby Immunology,' W. H. Freeman (6th ed.), New York, New York, USA.

Kiseleva, E. P., Mikhailopulo, K. I., Novik, G. I., Szwajcer Dey, E., Zdorovenko E. L., Shashkov A. S. \& Knirel, Y. A. (2013). "Isolation and Structural Identification of Glycopolymers of Bifidobacterium Bifidum BIM B-733D as Putative Players in Pathogenesis of Autoimmune Thyroid Diseases," Beneficial Microbes, 4 (4) 375391.

Kiso, Y., Furmaniak, J., Morteo, C. \& Rees Smith, B. (1992). "Analysis of Carbohydrate Residues on Human Thyroid Peroxidase (TPO) and Thyroglobulin (Tg) and Effects of Deglycosylation, Reduction and Unfolding on Autoantibody Binding," Autoimmunity, 12 (4) 259-269.

Kivity, S., Agmon-Levin, N., Blank, M. \& Shoenfeld, Y. (2009). "Infections and Autoimmunity - Friends or Foes?," Trends in Immunology, 30 (8) 409-414. 
Klis, F. M., de Jong, M., Brul, S. \& de Groot, P. W. J. (2007). "Extraction of Cell SurfaceAssociated Proteins from Living Yeast Cells," Yeast, 24 (4) 253-258.

Kohm, A. P., Carpentier, P. A. \& Miller, S. D. (2003). "Regulation of Experimental Autoimmune Encephalomyelitis (EAE) by CD4+CD25+ Regulatory T Cells," Novartis Foundation Symposium, 252 (0 45-52.

Kohno, Y., Naito, N., Hiyama, Y., Yoshio, N., Suzuki, N., Tarutani, O., Niimi, H., Nakajima, H. \& Hosoya, T. (1988). "Thyroglobulin and Thyroid Peroxidase Share Common Epitopes Recognized by Autoantibodies in Patients with Chronic Autoimmune Thyroiditis," The Journal of Clinical Endocrinology and Metabolism, 67 (5) 899907.

Kouskoff, V., Famiglietti, S., Lacaud, G., Lang, P., Rider, J. E., Kay, B. K., Cambier, J. C. \& Nemazee, D. (1998). “Antigens Varying in Affinity for the B Cell Receptor Induce Differential B Lymphocyte Responses," Journal of Experimental Medicine, 188 (8) 1453-1464.

Lee, C. G., Da Silva, C. A., Lee, J.- Y., Hartl, D. \& Elias, J. A. (2008). "Chitin Regulation of Immune Responses: An Old Molecule with New Roles," Current Opinion in Immunology, 20 (6) 684-689.

Lindberg, B., Svensson, J., Ericsson, U. B., Nilsson, P., Svenonius, E. \& Ivarsson, S. A. (2001). "Comparison of Some Different Methods for Analysis of Thyroid Autoantibodies: Importance of Thyroglobulin Autoantibodies," Thyroid, 11 (3) 265-269.

Liu, M., Yue, X., Dai, Z., Ma, Y., Xing, L., Zha, Z., Liu, S. \& Li, Y. (2009). "Novel ThromboResistant Coating Based on IronPolysaccharide Complex Multilayers," Applied Materials and Interfaces, 1 (1) 113123.

Liu, W., Sohn, H. W., Tolar, P. \& Pierce, S. K. (2010). "It's All about Change: The AntigenDriven Initiation of B-Cell Receptor Signaling," Cold Spring Harbor Perspectives in Biology, 2 (7) a002295.
Lleo, A., Invernizzi, P., Gao, B., Podda, M. \& Gershwin, E. (2010). "Definition of Human Autoimmunity - Autoantibodies versus Autoimmune Disease," Autoimmunity Reviews, 9 (5) A259-A266.

Londei, M., Bottazzo, G. F. \& Feldmann, M. (1985). "Human T-Cell Clones from Autoimmune Thyroid Glands: Specific Recognition of Autologous Thyroid Cells," Science, 228 (4695) 85-89.

Luo, P., Agadjanyan, M., Qiu, J., Westerink, M. A., Steplewski, Z. \& Kieber-Emmons, T. (1998). "Antigenic and Immunological Mimicry of Peptide Mimotopes of Lewis Carbohydrate Antigens," Molecular Immunology, 35 (13) 865 - 879.

Luo, P., Canziani, G., Cunto-Amesty, G. \& Kieber-Emmons, T. (2000). “A Molecular Basis for Functional Peptide Mimicry of a Carbohydrate Antigen," The Journal of Biological Chemistry, 275 (21) 1614616154.

MacKenzie, W. A., Schwartz, A. E., Friedman, E. W. \& Davies, T. F. (1987). "Intrathyroidal T Cell Clones from Patients with Autoimmune Thyroid Disease," Journal of Clinical Endocrinology and Metabolism, 64 (4) 818-824.

Maina, N. H., Tenkanen, M., Maaheimo, H., Juvonen, R. \& Virkki, L. (2008). "NMR Spectroscopic Analysis of Exopolysaccharides Produced by Leuconostoc Citreum and Weissella Confusa," Carbohydrate Research, 343 (9) 1446-1455.

Mankaï, A., Thabet, Y., Manoubi, W., Achour, A., Sakly, W. \& Ghedira, I. (2013). "AntiSaccharomyces Cerevisiae Antibodies are Elevated in Graves' Disease but Not in Hashimoto's Thyroiditis," Endocrine Research, 38 (2) 98-104.

Martins, F. S., Silva, A. A., Vieira, A. T., Barbosa, F. H., Arantes, R. M., Teixeira, M. M. \& Nicoli, J. R. (2009). "Comparative Study of Bifidobacterium Animalis, Escherichia Coli, Lactobacillus Casei and Saccharomyces Boulardii Probiotic 
Properties," Archives of Microbiology, 191 (8) 623-630.

Martocchia, A. \& Falaschi, P. (2007). "Amino Acid Sequence Homologies between HCV Polyprotein and Thyroid Antigens," Internal and Emergency Medicine, 2 (1) 65-67.

McLachlan, S. M. \& Rapoport, B. (1989). "Evidence for a Potential Common T-Cell Epitope between Human Thyroid Peroxidase and Human Thyroglobulin with Implications for the Pathogenesis of Autoimmune Thyroid Disease," Autoimmunity 5 (1-2) 101-106.

Mitterdorfer, G., Mayer, H. K., Kneifel, W. \& Viernstein, H. (2002). "Clustering of Saccharomyces Boulardii Strains within the Species S. Cerevisiae Using Molecular Typing Techniques," Journal of Applied Microbiology, 93 (4) 521-530.

Mond, J. J., Lees, A. \& Snapper, C. M. (1995). “T Cell-Independent Antigens Type 2," Annual Review of Immunology, 13 (O 655692.

Moura, E. G., Pazos-Moura, C. C., Yokoyama, N., Dorris, M. L. \& Taurog, A. (1991). "Enzymatic Deglycosylation of Porcine Thyroid Peroxidase: Effects on Catalytic Activity and Immunoreactivity," Acta Endocrinologica (Copenhagen), 124 (1) 107-114.

Moussa, T. A. A. \& Khalil, N. M. (2012). "Solid-State Fermentation for the Production of Dextran from Saccharomyces Cerevisiae and its Cytotoxic Effects," Life Science Journal, 9 (4) 2210-2218.

Muixi, L., Alvarez, I. \& Jaraquemada, D. (2008). "Peptides Presented in Vivo by HLA-DR in Thyroid Autoimmunity," Advances in Immunology, 99 (0 165-209.

Münz, C., Lünemann, J. D., Getts, M. T. \& Miller, S. D. (2009). "Antiviral Immune Responses: Triggers of or Triggered by Autoimmunity?," Nature Reviews Immunology, 9 (4) 246-258.
Neiser, S., Wilhelm, M., Schwarz, K., Funk, F., Geisser, P. \& Burckhardt, S. (2011). "Assessment of Dextran Antigenicity of Intravenous Iron Products by an Immunodiffusion Assay," Portuguese Journal of Nephrology and Hypertension, 25 (3) 219-224.

Noelle, R. J. \& Erickson, L. D. (2005). "Determinations of B cell Fate in Immunity and Autoimmunity," Current Directions in Autoimmunity 8 () 1-24.

Núñez, Y. P., Carrascosa, A. V., González, R., Polo, M. C. \& Martínez-Rodríguez, A. (2006). "Isolation and Characterization of a Thermally Extracted Yeast Cell Wall Fraction Potentially Useful for Improving the Foaming Properties of Sparkling Wines," Journal of Agricultural and Food Chemistry, 54 (20) 7898-7903.

Oldstone, M. B. A. (1998). "Molecular Mimicry and Immune-Mediated Diseases," FASEB Journal, 12 (13) 1255-1265.

Oldstone, M. B. A. (2005). "Molecular Mimicry, Microbial Infection, and Autoimmune Disease: Evolution of the Concept," Current Topics in Microbiology and Immunology, 296 (0 1-17.

Paul, A., Geetha, M., Chacko, B. K. \& Appukuttan, P. S. (2009). "Multiple Specificity of Human Serum DextranBinding Immunoglobulin: Alpha $(1 \rightarrow 6)$ and Beta $(1 \rightarrow 3)$-Linked Glucose and Alpha $(1 \rightarrow 3)$-Linked Galactose in Natural Glycoconjugates are Recognized," Immunological Investigations, 38 (2) 153164.

Pecquet, S., Guillaumin, D., Tancrede, C. \& Andremontl, A. (1991). "Kinetics of Saccharomyces Cerevisiae Elimination from the Intestines of Human Volunteers and Effect of this Yeast on Resistance to Microbial Colonization in Gnotobiotic Mice," Applied and Environmental Microbiology, 57 (10) 3049-3051. 
Pelizon, A. C., Kaneno, R., Soares, A. M. V. C., Meira, D. A. \& Sartori, A. (2005). "Immunomodulatory Activities Associated with $\quad \beta$-Glucan Derived from Saccharomyces Cerevisiae," Physiological Research, 54 (5) 557-564.

Perrotti, N., Grunberger, G., Richert, N. D. \& Taylor, S. I. (1986). "Immunological Similarity between the Insulin Receptor and the Protein Encoded by the Src Oncogene," Endocrinology 118 (6) 23492354.

Petravić-Tominac, V., Zechner-Krpan, V., Berković, K., Galović, P., Herceg, Z., Srečec, S. \& Špoljarić, I. (2011). "Rheological Properties, Water-Holding and Oil-Binding Capacities of Particulate $\beta$-Glucans Isolated from Spent Brewer's Yeast by Three Different Procedures," Food Technology and Biotechnology, 49 (1) 56-64.

Phenekos, C., Vryonidou, A., Gritzapis, A. D., Baxevanis, C. N., Goula, M. \& Papamichail, M. (2004). "Th1 and Th2 Serum Cytokine Profiles Characterize Patients with Hashimoto's Thyroiditis (Th1) and Graves' Disease (Th2)," Neuroimmunomodulation, 11 (4) 209-213.

Pitarch, A., Nombela, C. \& Gil, C. (2008). "Cell Wall Fractionation for Yeast and Fungal Proteomics," Methods in Molecular Biology, 425 (0 217-239.

Pordeus, V., Szyper-Kravitz, M., Levy, R. A., Vaz, N. M. \& Shoenfeld, Y. (2008). "Infections and Autoimmunity: A Panorama," Clinical Reviews in Allergy and Immunology 34 (3) 283-299.

Potluková, E. \& Limanová, Z. (2007). “The Role of Complement in Autoimmune Thyroid Disorders," Casopis Lekaru Ceskych, 146 (3) 210-214 (in Czech).

Qader, S. A. U. L., Iqbal, L., Aman, A., Shireen, E. \& Azhar, A. (2005). "Production of Dextran by Newly Isolated Strains of Leuconostoc Mesenteroides PCSIR-4 and PCSIR-9," Turkish Journal of Biochemistry, 31 (1) 21-26.
Qin, Q., Liu, P., Liu, L., Wang, R., Yan, N., Yang, J., Wang, X., Pandey, M. \& Zhang, J. A. (2012). "The Increased but NonPredominant Expression of Th17- and Th1Specific Cytokines in Hashimoto's Thyroiditis but Not in Graves' Disease," Brazilian Journal of Medical and Biological Research, 45 (12) 1202-1208.

Rebuffat, S. A., Nguyen, B., Robert, B., Castex, F. \& Peraldi-Roux, S. (2008). "Antithyroperoxidase Antibody-Dependent Cytotoxicity in Autoimmune Thyroid Disease," The Journal of Clinical Endocrinology and Metabolism, 93 (3) 929934.

Reyes-Becerril, M., Ascencio-Valle, F., Meseguer, J., Tapia-Paniagua, S. T., Moriñigo, M. A. \& Esteban M. Á. (2012). "Debaryomyces Hansenii L2-Enriched Diet Enhances the Immunity Status, Gene Expression and Intestine Functionality in Gilthead Seabream (Sparus Aurata L.)," Aquaculture Research, 43 (8) 1107-1118.

Ringold, D. A., Nicoloff, J. T., Kesler, M., Davis, H., Hamilton, A. \& Mack, T. (2002). "Further Evidence for a Strong Genetic Influence on the Development of Autoimmune Thyroid Disease: The California Twin Study," Thyroid, 12 (8) 647-653.

Rizzo, M., Rossi, R. T., Bonaffini, O., Scisca, C., Altavilla, G., Calbo, L., Rosanò, A., Sindoni, A., Trimarchi, F. \& Benvenga, S. (2010). "Increased Annual Frequency of Hashimoto's Thyroiditis between Years 1988 and 2007 at a Cytological Unit of Sicily," Annales d' Endocrinologie (Paris), 71 (6) 525-534.

Roep, B. O. (2003). "Molecular Mimicry in Autoimmune Neurological Disease after Viral Infection," Current Medicinal Chemistry, 10 (19) 1939-1943.

Root-Bernstein, R., Vonck, J. \& Podufaly, A. (2009). "Antigenic Complementarity between Coxsackie Virus and Streptococcus in the Induction of Rheumatic Heart Disease and Autoimmune Myocarditis," Autoimmunity, 42 (1) 1-16. 
Rose, N. R. (2008). "The Adjuvant Effect in Infection and Autoimmunity," Clinical Reviews in Allergy and Immunology, 34 (3) 279-282.

Ruf, J., Feldt-Rasmussen, U., Hegedüs, L., Ferrand, M. \& Carayon, P. (1994). "Bispecific Thyroglobulin and Thyroperoxidase Autoantibodies in Patients with Various Thyroid and Autoimmune Diseases," The Journal of Clinical Endocrinology and Metabolism, 79 (5) 1404-1409.

Rumbo, M., Nempont, C., Kraehenbuhl, J. P. \& Sirard, J. C. (2006). "Mucosal Interplay among Commensal and Pathogenic Bacteria: Lessons from Flagellin and TollLike Receptor 5," FEBS Letters, 580 (12) 2976-2984.

Sack, J., Zilberstein, D., Barile, M. F., Lukes, Y. G., Baker, J. R. Jr, Wartofsky, L. \& Burman, K. D. (1989). "Binding of Thyrotropin to Selected Mycoplasma Species: Detection of Serum Antibodies against a Specific Mycoplasma Membrane Antigen in Patients with Autoimmune Thyroid Disease," Journal of Endocrinological Investigation, 12 (2) 77-86.

Salamero, J., Remy, J. J., Michel-Bechet, M. \& Charreire, J. (1987). "Experimental Autoimmune Thyroiditis Induced by a 5-10 kDa Tryptic Fragment from Porcine Thyroglobulin," European Journal of Immunology, 17 (6) 843-848.

Sarwat, F., Qader, S. A. U., Aman, A. \& Ahmed, N. (2008). "Production and Characterization of a Unique Dextran from an Indigenous Leuconostoc Mesenteroides CMG713," International Journal of Biological Sciences, 4 (6) 379-386.

Shakib, F. \& Stanworth, D. R. (1980). "Human IgG Subclasses in Health and Disease. Part I," La Ricerca in clinica e in laboratorio, 10 (3) 463-479.

Shih, T.- A. Y., Roederer, M. \& Nussenzweig, M. C. (2002). "Role of Antigen Receptor Affinity in $\mathrm{T}$ Cell-Independent Antibody Responses in Vivo," Nature Immunology 3 (4) 399-406.
Sibirny, A. A. \& Voronovsky, A. Y. (2009). "Candida Fermata (Debareomyces Hansenii)," In : T. Satyanarayana and G. Kunze (eds.), Yeast Biotechnology: Diversity and Applications, Springer Science + Business Media B.V., Berlin, Germany, 85112.

Simionescu, L., Zamfir-Grigorescu, D., Dimitriu, V. \& Aman, E. (1983). “An Improved Procedure for the Preparation of the Human Thyroglobulin and the Development of a Thyroglobulin Autoantibody Kit," Endocrinologie, 21 (2) 113-121.

Simmonds, M. J. \& Gough, S. C. L. (2004). "Unraveling the Genetic Complexity of Autoimmune Thyroid Disease: HLA, CTLA4 and Beyond," Clinical and Experimental Immunology, 136 (1) 1-10.

Salmaso, C., Olive, D., Pesce, G. \& Bagnasco, M. (2002). "Costimulatory Molecules and Autoimmune Thyroid Diseases," Autoimmunity, 35 (3) 159-167.

Sfriso, P., Ghirardello, A., Botsios, C., Tonon, M., Zen, M., Bassi, N., Bassetto, F. \& Doria, A. (2010). "Infections and Autoimmunity: The Multifaceted Relationship," Journal of Leukocyte Biology, 87 (3) 385-395.

Stassi, G. \& De Maria, R. (2002). "Autoimmune Thyroid Disease: New Models of Cell Death in Autoimmunity," Nature Reviews Immunology, 2 (3) 195-204.

Tadayoshi, M., Takashi, H., Yoshihiro, K., Yukio, O., Yoshihide, F. \& Shiro, H. (1982). "Immunological Similarity of NCA (NonSpecific Cross-Reacting Antigen) in Feces with Alpha 1-Acid Glycoprotein," Clinica Chimica Acta, 122 (2) 161-168.

Thomas, D., Karachaliou, F., Kallergi, K., Vlachopapadopoulou, E., Antonaki, G., Chatzimarkou, F., Fotinou, A., Kaldrymides P. \& Michalacos, S. (2008a). "Herpes Virus Antibodies Seroprevalence in Children with Autoimmune Thyroid Disease," Endocrine, 33 (2) 171-175. 
Thomas, D., Liakos, V., Michou, V., Kapranos, N., Kaltsas, G., Tsilivakos, V. \& Tsatsoulis, A. (2008b). "Detection of Herpes Virus DNA in Post-Operative Thyroid Tissue Specimens of Patients with Autoimmune Thyroid Disease," Experimental and Clinical Endocrinology \& Diabetes, 116 (1) 35-39.

Thrasyvoulides, A. \& Lymberi, P. (2004). "Antibodies Cross-Reacting with Thyroglobulin and Thyroid Peroxidase are Induced by Immunization of Rabbits with an Immunogenic Thyroglobulin 20mer Peptide," Clinical \& Experimental Immunology, 138 (3) 423-429.

Tomer, Y. (2010). “Genetic Susceptibility to Autoimmune Thyroid Disease: Past, Present, and Future," Thyroid, 20 (7) 715725.

Tomer, Y. \& Villanueva, R. (2004). "Infection and Autoimmune Thyroid Diseases," In : Y. Shoenfeld and N. R. Rose (eds.), Infection and autoimmunity, Elsevier, Amsterdam, Netherlands, 515530.

Tozzoli, R., Barzilai, O., Ram, M., Villalta, D., Bizzaro, N., Sherer, Y. \& Shoenfeld, Y. (2008). "Infections and Autoimmune Thyroid Diseases: Parallel Detection of Antibodies against Pathogens with Proteomic Technology," Autoimmunity Reviews, 8 (2) 112-115.

Tsyganova, O. V., Kiseleva, E. P., Vashkevich, I. I. \& Sviridov, O. V. (2006a). 'Isolation of Autoantibodies to Human Thyroid Peroxidase by Antigen-Affinity Chromatography and their Application in Immunoassay,' Proceedings of the National Academy of Sciences of Belarus, Series of Chemical Sciences, (1) 64-71 (in Russian).

Tsyganova, O. V., Kiseleva, E. P., Vashkevich, I. I., Priadko, A. G. \& Sviridov, O. V. (2006b). "Characteristics of Immunoaffinity Chromatography and a New Method for Isolation of Human Thyroid Peroxidase from Subcellular Fractions of Thyroid Gland," Applied Biochemistry and Microbiology, 42 (2) 236-246.
Tsyganova, O. V., Kiseleva, E. P., Vashkevich, I. I., Priadko, A. G. \& Sviridov, O. V. (2006c). "Characteristics of Monoclonal Antibodies against Human Thyroid Peroxidase for Use in Immunoaffinity Chromatography and Immunoassays," Applied Biochemistry and Microbiology, 42 (1) 98-105.

Van Cleve, J. W., Schacfer, W. C. \& Rist, C. E. (1956). "The Structure of NRRL B-512F Dextran, Methylation Studies," Journal of the American Chemical Society 78 (17) 4435-4438.

Van der Aa Kühle, A., Skovgaard, K. \& Jespersen, L. (2005). "In Vitro Screening of Probiotic Properties of Saccharomyces Cerevisiae Var. Boulardii and Food-Borne Saccharomyces Cerevisiae Strains," International Journal of Food Microbiology, 101 (1) 29-39.

Vanderpump, M. P., Turnbridge, W. N., French, J. M., Appleton, D., Bates, D., Clark, F., Grimley Evans, J., Hasan, D. M., Rodger,s H., Tunbridge, F. T. \& Young, E. T. (1995). "The Incidence of Thyroid Disorders in the Community: A Twenty-Year Follow-Up of the Whickham Survey," Clinical Endocrinology, 43 (1) 55-68.

Vetriselvi, J., Saravanamurthy, R. \& Dhivaharan, V. (2010). Chapter 1. Biotechnological Potential and Industrial Applications of Yeast, In: Industrial Exploitation of Microorganisms. D. K. Maheshwari, R. C. Dubey and R. Saravanamurthy (eds.), I.K. International Publishing House Pvt. Ltd., New Delhi, India, $1-11$.

von Herrath, M. G., Fujinami, R. S. \& Whitton, J. L. (2003). "Microorganisms and Autoimmunity: Making the Barren Field Fertile?," Nature Reviews, 1 (2) 151-157.

Weetman, A. P. (1997). "New Aspects of Thyroid Immunity," Hormone Research, 48 (Suppl. 4) 51-54.

Weetman, A. P. (2003). "Autoimmune Thyroid Disease: Propagation and Progression," European Journal of Endocrinology, 148 (1) 1-9. 
Wegner, N., Wait, R. \& Venables, P. J. (2009). "Evolutionarily Conserved Antigens in Autoimmune Disease: Implications for an Infective Aetiology," The International Journal of Biochemistry \& Cell Biology, 41 (2) 390-397.

Wszolek, M., Kupiec-Teahan, B., Skov Guldager, H. \& Tamime, A. Y. (2006). Chapter 8. Production of Kefir, koumiss and Other Related Products, In : Fermented Milks, A. Y. Tamime (ed.), Blackwell Science Ltd., Oxford, UK, 174-216.

Wucherpfennig, K. W., Allen, P. M., Celada, F., Cohen, I. R., De Boer, R., Garcia, K. C., Goldstein, B., Greenspan, R., Hafler, D., Hodgkin, P., Huseby, E. S., Krakauer, D. C., Nemazee, D., Perelson, A. S., Pinilla, C., Strong, R. K. \& Sercarz, E. E. (2007). "Polyspecificity of $\mathrm{T}$ Cell and B Cell Receptor Recognition," Seminars in Immunology, 19 (4) 216-224.

Xie, L.- D., Gao, Y., Li, M.- R., Lu, G.- Z. \& Guo, X.- H. (2008). "Distribution of Immunoglobulin G Subclasses of AntiThyroid Peroxidase Antibody in Sera from Patients with Hashimoto's Thyroiditis with Different Thyroid Functional Status," Clinical and Experimental Immunology, 154 (2) 172-176.

Yang, L., Biswas, M. E. \& Chen, P. (2003). "Study of Binding between Protein A and Immunoglobulin G Using a Surface Tension Probe," Biophysical Journal 84 (1) 509-522.

Yazıcı, D., Aydın, S. Z., Yavuz, D., Tarçın, O., Deyneli, O., Direskeneli, H. \& Akalın S. (2010). "Anti-Saccaromyces Cerevisiae Antibodies (ASCA) are Elevated in Autoimmune Thyroid Disease," Endocrine, 38 (2) 194-198.
Yukio, O., Yoshihide, F., Shiro, H., Tadayoshi, M., Manabu, Y., Takashi, H. \& Yoshihiro, K. (1982). "Immunological Similarity of CEA with Alpha 1-Acid Glycoprotein (Orosomucoid)," Clinica Chimica Acta, 1982 122(2):145-160.

Zeuthen, L. H., Fink, L. N. \& Frøkiær, H. (2008). "Toll-Like Receptor 2 and Nucleotide-Binding Oligomerization Domain-2 Play Divergent Roles in the Recognition of Gut-Derived Lactobacilli and Bifidobacteria in Dendritic Cells," Immunology, 124 (4) 489-502.

Zhang, M., Cui, S. W., Cheung, P. C. K. \& Wang, Q. (2007). "Antitumor Polysaccharides from Mushrooms: A Review on Their Isolation Process, Structural Characteristics and Antitumor Activity," Trends in Food Science and Technology, 18 (1) 4-19.

Zhang, T., Lei, J., Yang, H., Xu, K., Wang, R. \& Zhang, Z. (2011). "An Improved Method for Whole Protein Extraction from Yeast Saccharomyces Cerevisiae," Yeast 28 (11) 795-798.

Zhang, Y., Gao, Y., Li, M., Xie, L., Huang, Y., Gao, Y. \& Guo X. (2010). "Avidity of Thyroglobulin Antibody in Sera from Patients with Hashimoto's Thyroiditis with Different Thyroid Functional Status," Clinical and Experimental Immunology, 161 (1) 65-70.

Zimmer, K.- P., Scheumann, G. F., Bramswig, J., Bocker, W., Harms, E. \& Schmid, K. W. (1997). "Ultrastructural Localization of IgG and TPO in Autoimmune Thyrocytes Referring to the Transcytosis of IgG and the Antigen Presentation of TPO," Histochemistry and Cell Biology, 107 (2) 115-120. 


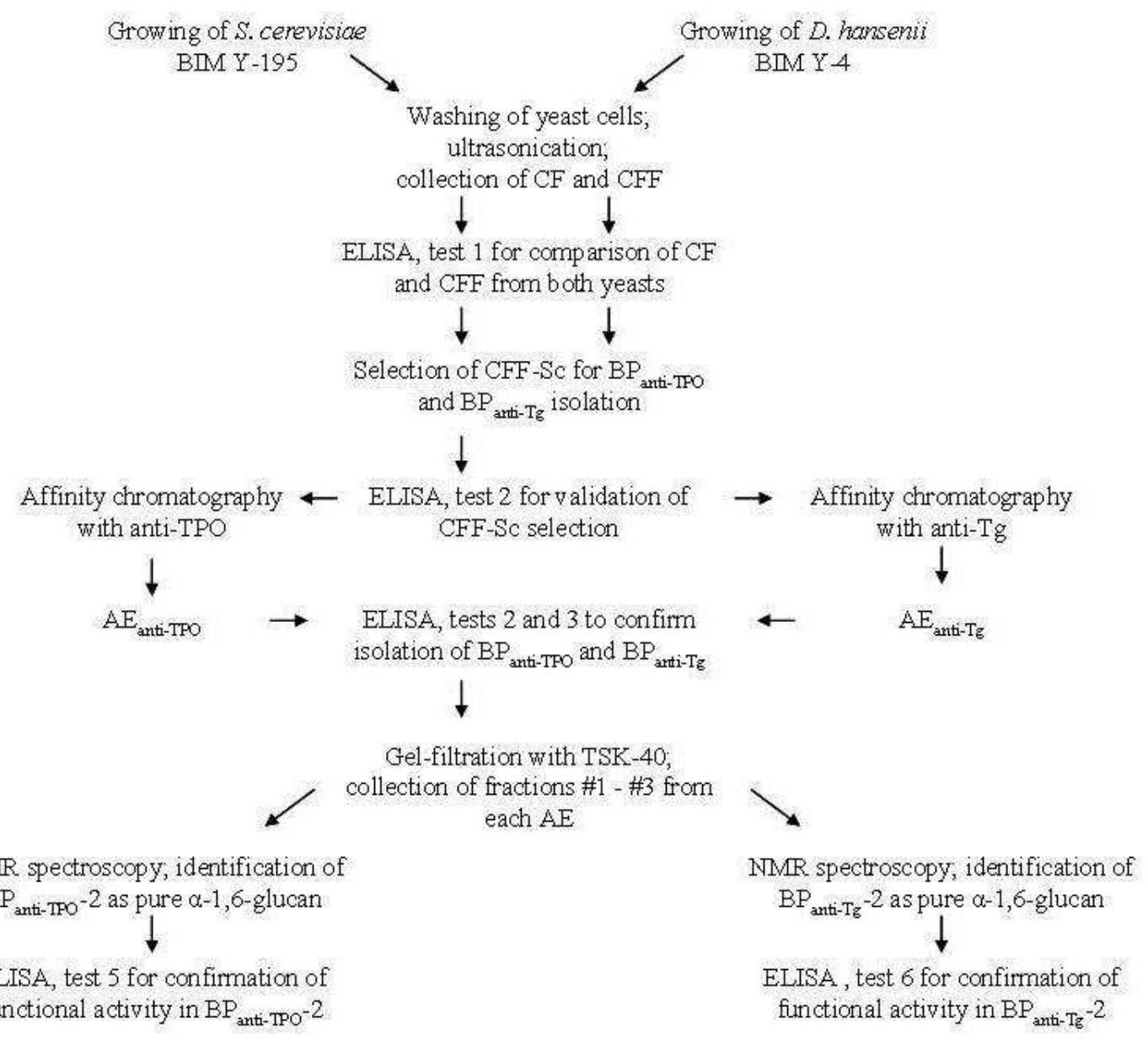

Appendix 1. Methodological Steps of the Study

Appendix 2. Immobilized Items and Primary Reagents Added in Wells at the First Stage of ELISA Tests.

Table 3. Immobilized Items and Primary Reagents Added in Wells at the First Stage of ELISA test 1. Test 1 was Performed to Detect Functional Activity Characteristic of $\mathrm{BP}_{\text {anti- }}$

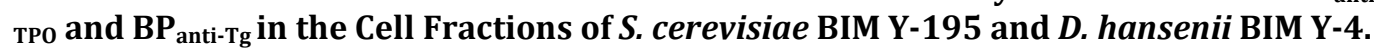
Each Table Cell Means Two Identical Wells.

\begin{tabular}{|c|c|c|c|c|c|c|c|}
\hline & & \multicolumn{6}{|c|}{ Immobilized item } \\
\hline & & \multicolumn{2}{|c|}{ S. cerevisiae BIM Y-195 } & \multicolumn{2}{|c|}{ D. hansenii BIM Y-4 } & \multirow[t]{2}{*}{ TPO } & \multirow[t]{2}{*}{$\mathrm{Tg}$} \\
\hline & & $\mathrm{CF}$ & CFF & $\mathrm{CF}$ & CFF & & \\
\hline \multirow{7}{*}{ 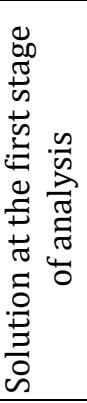 } & 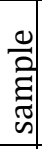 & \multicolumn{6}{|c|}{ Serum samples from second and third groups, diluted 100 -fold by buffer 3} \\
\hline & वे & 1 & 1 & 1 & 1 & 1 & 1 \\
\hline & ? & 2 & 2 & 2 & 2 & 2 & 2 \\
\hline & $\Xi$ & 3 & 3 & 3 & 3 & 3 & 3 \\
\hline & 0 & & & & & & \\
\hline & है & 47 & 47 & 47 & 47 & 47 & 47 \\
\hline & స్ట్రి & 48 & 48 & 48 & 48 & 48 & 48 \\
\hline
\end{tabular}


Table 4. Immobilized Items and Primary Reagents Added in Wells at the First Stage of

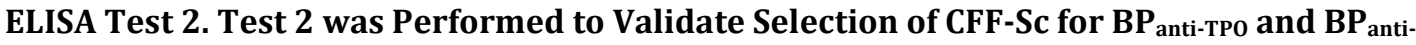
Tg Isolation. Each Table Cell Means Two Identical Wells.

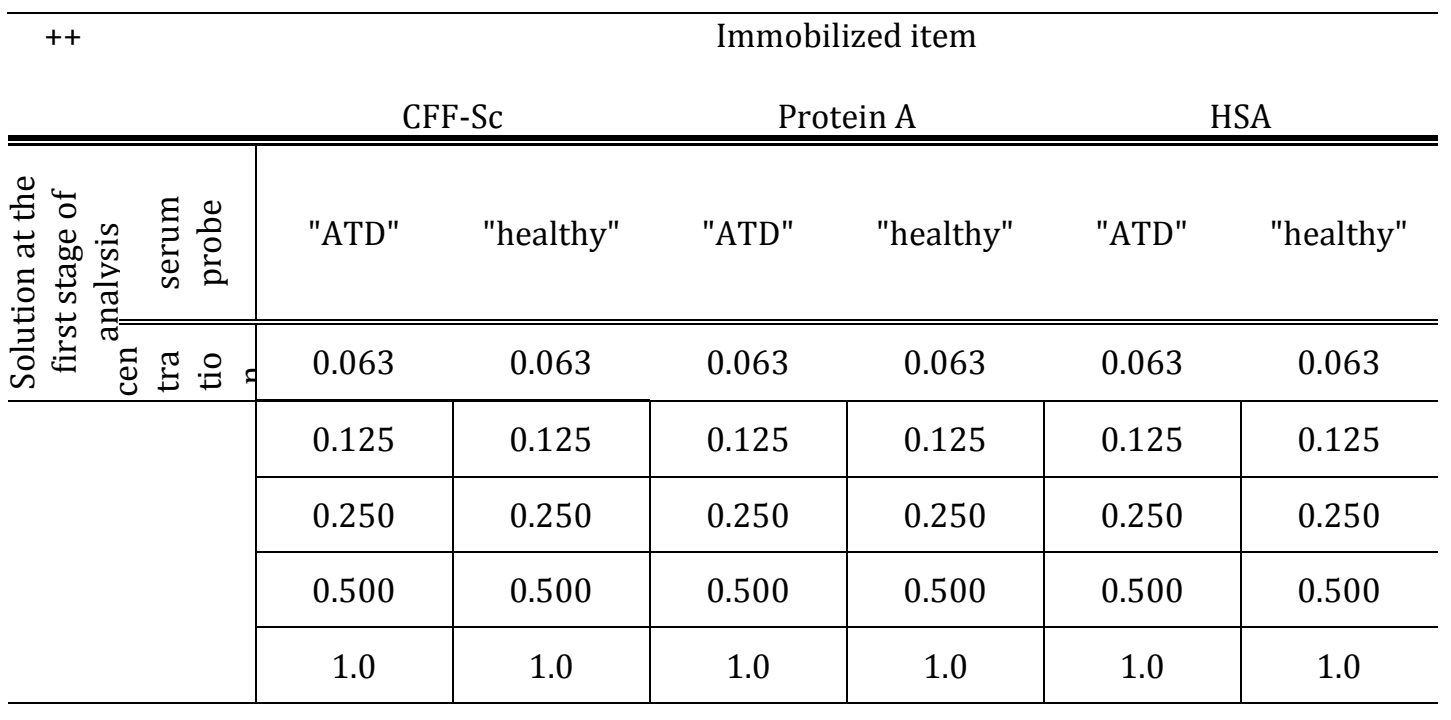

Table 5. Immobilized Items and Primary Reagents Added in Wells at the First Stage of ELISA Test 3. Test 3 was Performed to Prove that $\mathrm{AE}_{\text {anti-TPo }}$ and $\mathrm{AE}_{\text {anti-Tg }}$ Selectively Bind Anti-TPO and Anti-Tg. Each Table Cell Means Two Identical Wells.

\begin{tabular}{|c|c|c|c|c|c|c|c|c|c|}
\hline & & \multicolumn{8}{|c|}{ Immobilized item } \\
\hline & & \multicolumn{2}{|c|}{$\mathrm{AE}_{\mathrm{anti-TPO}}$} & \multicolumn{2}{|c|}{$\mathrm{AE}_{\text {anti-Tg }}$} & \multicolumn{2}{|c|}{ TPO } & \multicolumn{2}{|c|}{$\mathrm{Tg}$} \\
\hline \multirow{5}{*}{ 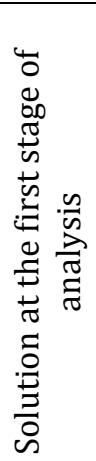 } & 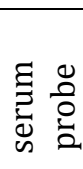 & "ATD" & $\begin{array}{c}\text { "health } \\
\text { y" }\end{array}$ & "ATD" & $\begin{array}{c}\text { "health } \\
\text { y" }\end{array}$ & "ATD" & $\begin{array}{c}\text { "health } \\
\text { y" }\end{array}$ & "ATD" & $\begin{array}{c}\text { "health } \\
\text { y" }\end{array}$ \\
\hline & \multirow{4}{*}{ 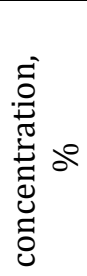 } & 0.0370 & 0.0370 & 0.0370 & 0.0370 & 0.0370 & 0.0370 & 0.0370 & 0.0370 \\
\hline & & 0.1111 & 0.1111 & 0.1111 & 0.1111 & 0.1111 & 0.1111 & 0.1111 & 0.1111 \\
\hline & & 0.3333 & 0.3333 & 0.3333 & 0.3333 & 0.3333 & 0.3333 & 0.3333 & 0.3333 \\
\hline & & 1.0 & 1.0 & 1.0 & 1.0 & 1.0 & 1.0 & 1.0 & 1.0 \\
\hline
\end{tabular}

Table 6. Immobilized Items and Primary Reagents Added in Wells at the First Stage of ELISA Test 4. Test 4 was Performed to Prove that $\mathrm{AE}_{\text {anti-TPo }}$ and $\mathrm{AE}_{\text {anti-Tg }}$ Compete with TPO and Tg, Respectively, for Binding of the Appropriate Autoantibodies. Each Table Cell Means Two Identical Wells.

\begin{tabular}{|c|c|c|c|c|c|c|}
\hline & \multicolumn{4}{|c|}{ Immobilized item } \\
\hline & & & $\mathrm{AE}_{\text {anti-TPO }}$ & $\mathrm{AE}_{\text {anti-Tg }}$ & TPO & $\mathrm{Tg}$ \\
\hline \multirow{6}{*}{ 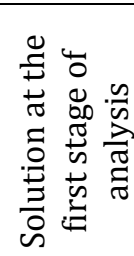 } & \multicolumn{2}{|l|}{ source of Ig } & \multicolumn{4}{|c|}{ probe "ATD" } \\
\hline & \multicolumn{2}{|l|}{ competitor } & TPO & $\mathrm{Tg}$ & TPO & $\mathrm{Tg}$ \\
\hline & \multirow{4}{*}{$\begin{array}{c}\text { concentration } \\
\text { of competitor, } \\
\mathrm{mg} / \mathrm{L}\end{array}$} & $\mathrm{B}_{0}$ & 0 & 0 & 0 & 0 \\
\hline & & $\mathrm{B}_{1}$ & 40 & 33 & 40 & 33 \\
\hline & & $\mathrm{B}_{2}$ & 120 & 100 & 120 & 100 \\
\hline & & $\mathrm{B}_{3}$ & 360 & 300 & 360 & 300 \\
\hline
\end{tabular}


Table 7. Immobilized Items and Primary Reagents Added in Wells at the First Stage of ELISA Test 5. Test 5 was Performed to Confirm that the Fraction $\mathrm{BP}_{\text {anti-TPo-2 }}$ Contains

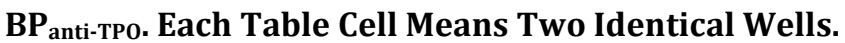

\begin{tabular}{|c|c|c|c|c|c|c|c|}
\hline & & \multicolumn{6}{|c|}{ Immobilized item } \\
\hline & & \multicolumn{2}{|c|}{$\mathrm{BP}_{\text {anti-TPO}}-2$} & \multicolumn{2}{|c|}{ TPO } & \multicolumn{2}{|c|}{ Protein A } \\
\hline \multirow{5}{*}{ 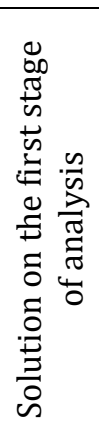 } & مص & anti-Tg & $\operatorname{tg} G$ & anti-Tg & $\operatorname{tgG}$ & anti-Tg & tIgG \\
\hline & \multirow{4}{*}{ 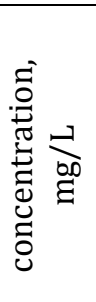 } & 1.2963 & 1.2963 & 1.2963 & 1.2963 & 1.2963 & 1.2963 \\
\hline & & 3.8889 & 3.8889 & 3.8889 & 3.8889 & 3.8889 & 3.8889 \\
\hline & & 11.6667 & 11.6667 & 11.6667 & 11.6667 & 11.6667 & 11.6667 \\
\hline & & 35.0 & 35.0 & 35.0 & 35.0 & 35.0 & 35.0 \\
\hline
\end{tabular}

Table 8. Immobilized Items and Primary Reagents Added in Wells at the First Stage of ELISA Test 6. Test 6 was Performed to Confirm that the Fraction $\mathrm{BP}_{\text {anti- } \mathrm{Tg}}-2$ Contains

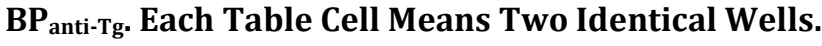

\begin{tabular}{|c|c|c|c|c|c|c|c|}
\hline & \multirow[b]{3}{*}{ 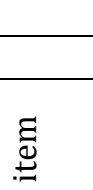 } & \multicolumn{6}{|c|}{ Immobilized item } \\
\hline & & \multicolumn{2}{|c|}{$\mathrm{BP}_{\text {anti-Tg }}-2$} & \multicolumn{2}{|c|}{$\mathrm{Tg}$} & \multicolumn{2}{|c|}{ Protein A } \\
\hline \multirow{5}{*}{ 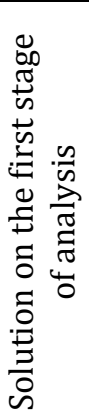 } & & anti-Tg & $\operatorname{tg} G$ & anti-Tg & $\operatorname{tIgG}$ & anti-Tg & $\operatorname{tIgG}$ \\
\hline & & 1.19 & 1.19 & 1.19 & 1.19 & 1.19 & 1.19 \\
\hline & i. & 3.56 & 3.56 & 3.56 & 3.56 & 3.56 & 3.56 \\
\hline & 苂 & 10.67 & 10.67 & 10.67 & 10.67 & 10.67 & 10.67 \\
\hline & & 32.0 & 32.0 & 32.0 & 32.0 & 32.0 & 32.0 \\
\hline
\end{tabular}

Appendix 3. ${ }^{1} \mathrm{H}$ NMR Spectrum of $\mathrm{BP}_{\text {anti-Tg }}-2$

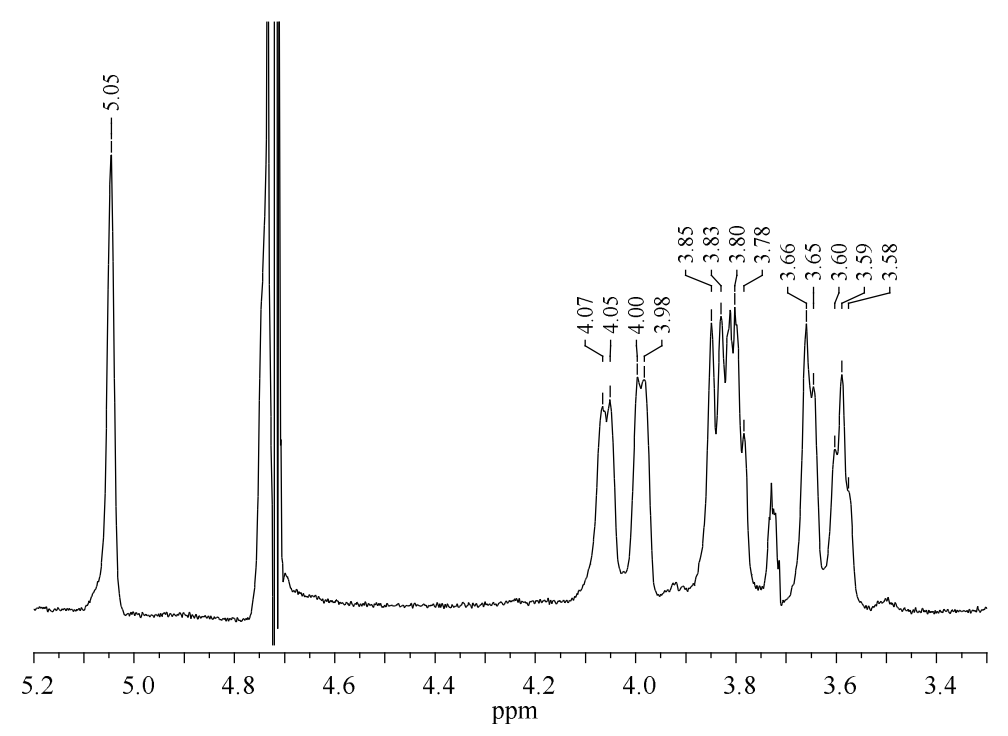

E. P. Kiseleva, K. I. Mikhailopulo, G. I. Novik, E. Szwajcer Dey, E. L. Zdorovenko, A. S. Shashkov and Y. A. Knirel (2014), Research in Immunology: An International Journal, DOI: 10.5171/2014.355367 